\title{
Research and Development of Electro-hydraulic Control Valves Oriented to Industry 4.0: A Review
}

\author{
Bing Xu, Jun Shen, Shihao Liu, Qi Su and Junhui Zhang*
}

\begin{abstract}
Electro-hydraulic control valves are key hydraulic components for industrial applications and aerospace, which controls electro-hydraulic motion. With the development of automation, digital technology, and communication technology, electro-hydraulic control valves are becoming more digital, integrated, and intelligent in order to meet the requirements of Industry 4.0. This paper reviews the state of the art development for electro-hydraulic control valves and their related technologies. This review paper considers three aspects of state acquisition through sensors or indirect acquisition technologies, control strategies along with digital controllers and novel valves, and online maintenance through data interaction and fault diagnosis. The main features and development trends of electro-hydraulic control valves oriented to Industry 4.0 are discussed.
\end{abstract}

Keywords: Hydraulic valves, Electro-hydraulic technology, Sensor, Control, Digital hydraulic, Fault diagnosis

\section{Introduction}

Since Pascal put forward the basic law of pressure transfer for static liquid, this concept has been developed for nearly four centuries. With the advantages of a high power density, large force output, and easiness to actualize linear motions, hydraulic transmission systems are widely used in industrial hydraulics and for mobile hydraulic machinery. Modern hydraulic control technology began after World War I. Hydraulic valves are critical components in many hydraulic systems where the flow rate, pressure, or actuators need to be controlled. There are many types of electro-hydraulic control valves, like proportion valves, flapper-nozzle valves, or other valves with electronic controllers. With the development of materials, manufacturing, electronic technology, and computer technology, more power has been injected into electro-hydraulic control valves along with new demands. Hydraulic valves are being developed to adapt

\footnotetext{
*Correspondence: benzjh@zju.edu.cn

State Key Laboratory of Fluid Power and Mechatronic Systems, Zhejiang University, Hangzhou 310027, China
}

to the changing world and market, which has become more versatile and powerful, as shown in Figure 1.

Industry 4.0 was proposed by the German government from a project with a high-tech strategy, which promotes the computerization of manufacturing [1]. Since the principles of Industry 4.0 have been applied by many companies, electro-hydraulic control valves also need to achieve features from Industry 4.0. What are the requirements of Industry 4.0 for electro-hydraulic control valves? The hydraulic valves should be available at remote terminals so they can be controlled and monitored. And the abilities of self-detection, fault diagnosis, function redefining, and integration should be added into valves for Industry 4.0. Digital technologies can make hydraulic valves accessible to the embedded system and they are linked to computers or mobile terminals. With the integration of digital controllers and other hardware like various transducers, the valve's functions could be customized and extensible, besides online remote monitoring and the diagnosis can be implemented through CANopen or other communication technologies. The demand for Industry 4.0 to achieve valve self-diagnosis is not limited to the detection of simple faults such as electronic faults with sensors. 


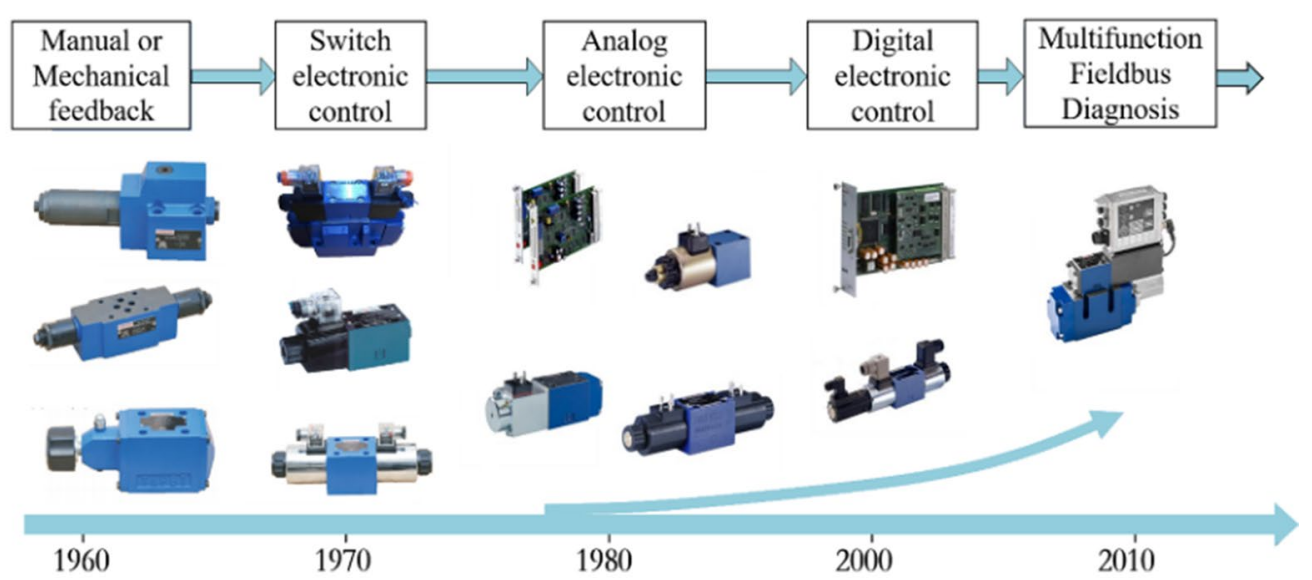

Figure 1 Development of electro-hydraulic control valves

Instead, intelligent and effective diagnosis of faults deep inside the valve can occur with limited state signals.

This paper aims to review the state-of-the-art research for electro-hydraulic control valves from the perspective of Industry 4.0. First, sensor technologies used on electro-hydraulic valves, which are the basis for state acquisition and diagnosis, are stated and some indirect state acquisition methods are presented. Then, an overview of the electronic controllers' development is provided with various actuators and control algorithms of the valves. In addition, the separate control of meter-in and meter-out and on/off valves are discussed with digital hydraulics. Furthermore, integrated communication technology and management software used for electro-hydraulic valves are summarized, which allows online remote monitoring, controlling, managing, and fault diagnosis possible. Finally, intelligent diagnosis methods for the inner faults of electro-hydraulic valves are reviewed, which includes data-based and model-based fault diagnosis methods.

\section{State Acquisition}

State acquisition is the basis of achieving digitization and intelligence for electro-hydraulic valves. Electro-hydraulic valves need to achieve autonomous control, remote fault diagnosis, and the construction of the Internet of Things through the acquisition of state quantities for each element. There are two kinds of existing state acquisition methods for electro-hydraulic valves: one is directly obtained by sensors; the other is obtained by indirect acquisition technologies. It can be observed from the valve's dynamic motion equation that the valve port pressure, valve port flow, valve spool displacement, and valve body temperature are the most important state variables for motion control and fault diagnosis. Electro-hydraulic control valves oriented to Industry 4.0 are expected to obtain complete state information of the valves and systems with the development of sensor technologies and indirect acquisition technologies.

\subsection{Direct State Acquisition by Sensors}

In order to achieve closed-loop controls or monitor the valves' states, sensors are used to obtain the states of the valves or other elements of the hydraulic systems. There are many types of sensors, such as pressure sensors, flow sensors, position sensors, pollution sensors, and particulate sensors, which can build a system state acquisition network for the valve to achieve the control function and the fault diagnosis function. External sensors transmit information of the system's state to the valves through a variety of communication modes, like Fieldbus, IO-Link, and sensor managers, which makes the valve an element with a sensing function. However, the external sensors bring difficulties with respect to the hardware installation, servicing, maintenance, and bringing extra costs for the cables and communication transmitters at the same time.

With the development of electronic technology and material technology, the miniaturization and integration level of modern sensors are much higher. Many manufacturers integrate a variety of sensors into the valves to improve the state acquisition capability of the valves. Atos AGMZO-RES integrates a pressure sensor at the pilot oil port to achieve closed-loop pressure control for the pilot stage valve. Eaton Axis Pro equips an integrated sensor adapter plate, which obtains the pressure for each port and the temperature of port $\mathrm{T}$ to provide process control and intelligent system diagnostics. Eaton CMA 200 series integrates internal membrane pressure sensors at each port to achieve independent closed-loop pressure control for each port. Lots of directional valves integrate 
displacement sensors using a linear variable differential transformer (LVDT), which has good compatibility and is convenient; however, it requires more installation space. The state acquisition and transmission modes of modern valves are shown in Figure 2. With a higher accuracy, a smaller size, and a better installation mode for the sensor, the state acquisition ability of the valve gradually increases, which is a necessary condition for Industry 4.0.

\subsection{Indirect State Acquisition Technologies}

The direct acquisition methods can solve some problems for state monitoring, such as the port pressure and the valve body temperature. However, monitoring the states in some valves will bring extra difficulties and costs, or the accuracy and sampling rate of the sensors are not satisfied with the requirements in some situations. Many researchers are using indirect acquisition methods to detect the spool displacement and flow rate, which are commonly seen.

Mature LVDT displacement measurement technology has been widely used in proportional valves. However, LVDT technology still has many difficulties in detecting displacements in the pilot stage spool of the pilot-operated proportional valve. Many studies have focused on analyzing the current, voltage, and inductance of the coil to estimate the displacement of the valve spool, as shown in Figure 3. Rahman et al. [2] proposed a method to estimate the position of solenoids by obtaining its incremental inductance in the high-current region and the validity of this method was verified by the implementation of

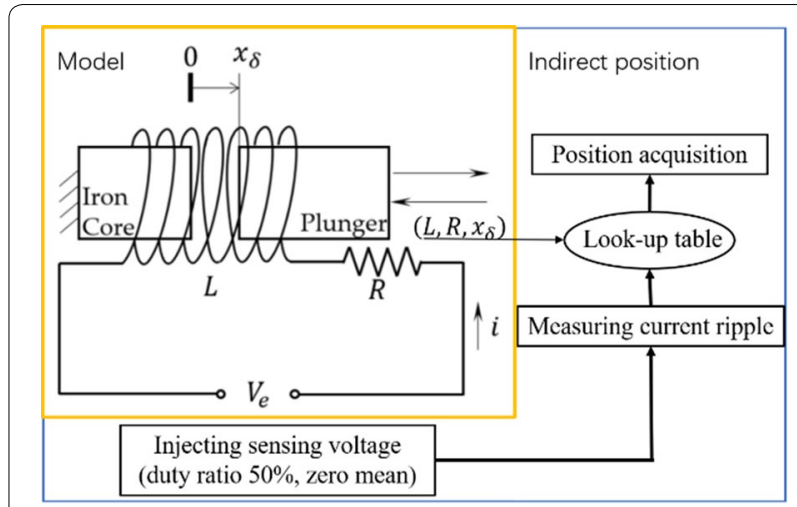

Figure 3 Schematic of the valve's solenoid and indirect position acquisition method

hardware. Rahman solved the position estimation problem and the estimation process was implemented on a digital signal processor (DSP) and computed in real-time. This method is suitable for any slow-moving single-phase reluctance motion device; however, the accuracy for position estimation is dependent on the inductance-positioncurrent characteristics of the device. Yudell et al. [3] proposed a method to predict the spool displacement by analyzing the current in the solenoid. This method allows a user to positively identify the beginning and the end of valve transition events by identifying the slope changes in the solenoid coil current traces. Proost proposed a method to estimate the pilot-operated proportional

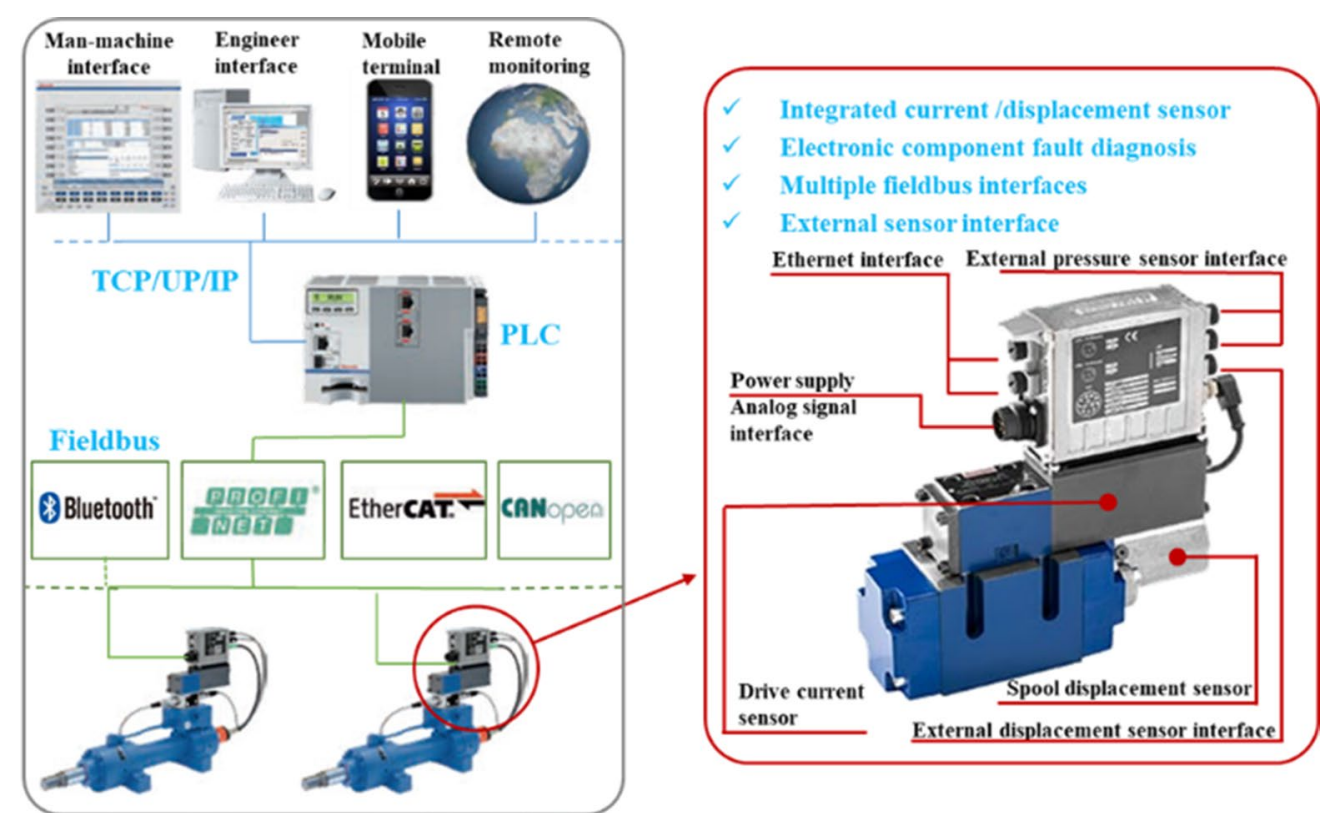

Figure 2 State acquisition and transmission 
solenoid actuator position by using the self-sensing principle. In comparison to the finite element simulations and experiments, Proost found that a change in the flux linkage with respect to the pilot stage spool position occurs. This change in the flux over the position interval is dependent on the frequency through the skin effect principle [4]. Braun et al. [5] proposed a method to estimate the spool displacement by building an observer. Kramer et al. [6] used differential inductance methods to solve this problem. The methods of analyzing the relationship of the solenoid's inductance and the spool displacement were modified in different ways in order to be more accurate and faster. Indirect displacement acquisition technologies can make up the limitations of the sensors, save costs, and enhance the valves' ability for state acquisition.

Flow rate is also an important parameter whether in the parameter transmission between the main stage spool and the pilot stage spool or in the performance of axis control systems. Integrated direct flow rate measurement is difficult to achieve and even the implementation will bring high costs. Therefore, mainstream detection can result in indirect acquisitions. In 1967, Merritt [7] put forward a classical empirical formula for calculating the flow rate of sharp edge throttles based on the Bernoulli equation. The most critical step is the calculation of the flow coefficient $C_{\mathrm{d}}$. In the following research, Merritt provided the fitting curve for the flow coefficient, the quadratic root of the Reynolds number, and the approximate value of the flow coefficient,which is 0.61 . However, with the increasing complexity of the internal structure of the valve body, some assumptions in the classical flow calculation formula cannot be satisfied. Therefore, a lot of research focuses on finding a universal flow coefficient fitting formula.

In a small opening, the flow coefficient fitting formula is based on the exponential function and supplements the formula according to the leakage flow law of the valve spool [8-10]. The formula has a good fitting effect on the curve measured by Merritt; however, the calculated flow coefficient under different working conditions will be distributed around the curve, which affects the accuracy of the flow rate calculation. Valdés et al. [11] and Dimitrov et al. [12] fully considered the influence of the valve body structure on the flow rate and adopted a computational fluid dynamics (CFD) simulation method to calculate the relationship differential pressure and the flow rate of the valve. This method can accurately calculate the flow rate through a specific valve structure; however, a lot of simulations are required to deal with the flow field changes caused by the different valve openings. At the same time, how to split the structure reasonably is a key problem that needs to be solved. Another method is to directly establish the relationship between the flow rate of the throttle valve and the pressure drop of the valve port. This can be calculated by measuring the pressure at both ends of the valve ports and the displacement of the valve spool. Das et al. [13] and Borghi et al. [14] used the polynomial equation with the flow rate as an independent variable to fit the pressure drop at both ends of the valve port for different valve openings. Åman et al. [15] also used the pressure difference at both ends of the valve port to fit the flow rate through the valve port on the basis of considering the influence of the flow patterns. However, this method still has the problem of an inaccurate flow coefficient in the process of flow calculation, which affects the accuracy of the flow calculation [16-18]. Wang et al. [19] measured the flow rate using an AdaBoost neural network to learn the flow rate change regulation affected by the spool displacement, pressure differential, and the temperature with a high accuracy and low overfitting. The AdaBoost neural network was determined to be capable of recognizing the characteristic shapes of the flow rate function with an accuracy of $\pm 2 \%$ as illustrated in Figure 4 . To acquire the flow rate indirectly, the fitting methods can deal with a complex valve body structure and methods like a neural network can provide new ideas.

State acquisition is important for electro-hydraulic control valves. The performance of state monitoring, controlling, and fault diagnosis all rely on the quality of the state information. Sensors that are highly integrated with a fast response and a high precision, along with indirect state acquisition technologies, are required for valves to be oriented to Industry 4.0.

\section{Control Technologies and Novel Valves}

\subsection{Electronic Controllers from Analog to Digital}

Electro-hydraulic control valves typically have electronic mechanical converters and feedback signal transduces,

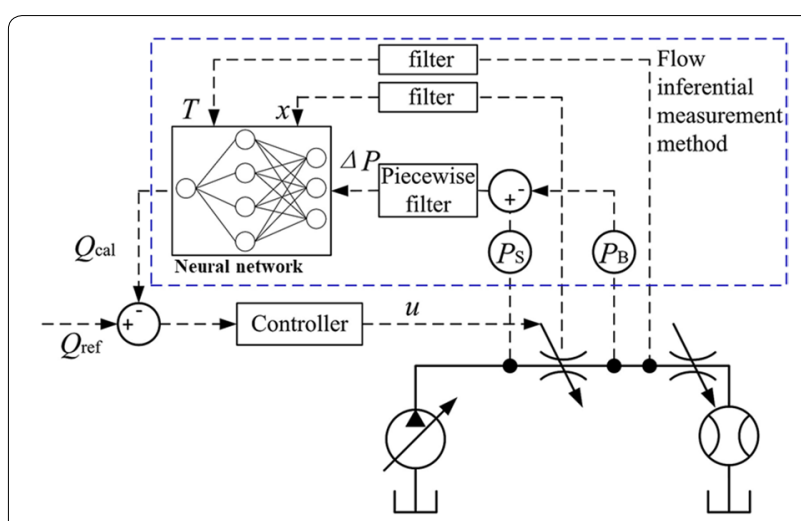

Figure 4 Flow measurement method based on the AdaBoost neural network 
which represents the output and input. In the 1970s, electrohydraulic control valves began to adopt electrical transducers, like hall-effect position transducers [20]. Furthermore, for a control system, the processing unit is essential to use control algorithms to deal with the input and output signals. The electronic controllers are the processing units. Since the late 1960s, the electronic controllers of the valves have experienced open-loop analog controllers, analog controllers with feedback, and digital controllers. With the development of integrated circuit chips, digital controllers have the advantages of being programmable, interactive, and they can be applied to a variety of fields besides electro-hydraulic valves [21, 22]. Analog electrical controllers from an earlier period made from analog components were gradually replaced by digital controllers, as displayed in Figure 5. A high speed and large capacity computing power can effectively achieve millisecond-level control cycles, which has significantly improved the real-time capability of hydraulic transmission and its controls [23].

Since digital controllers can load rewritable program codes and access different hardware, the electro-hydraulic control valves' functions have become more diverse and complete. What's more important is that digital controllers can integrate multiple functions on a single valve. For example, both uniform pressure drop valves and flow control valves are required to achieve pressure and flow hybrid control; however, one pressure and flow $(\mathrm{p} / \mathrm{Q})$ control valve can do all of these things. The combined $\mathrm{p} / \mathrm{Q}$ valves are attractive to industry, like injection molding machines, and there are also some studies for $\mathrm{P} / \mathrm{Q}$ valves. Helmut Schmidt University developed an electrorheological valve with full $\mathrm{p} / \mathrm{Q}$-functionality for servohydraulic applications [24]. The Zhejiang University of Technology also studied a $\mathrm{p} / \mathrm{Q}$ valve with digital controllers [25]. Another advanced function for electrohydraulic control valves with digital controllers is the axis control function. Traditionally, the external programmable logic controllers (PLCs) or other motion controllers are used to control the hydraulic cylinder. Axis control valves (ACV) put the control loop within the valve electronics. Electro-hydraulic control valves with digital controllers are versatile with the ability to close the position and force control loop, besides the flow and pressure control loop above. Many hydraulic companies are developing their axis control valves.

Although analog controllers don't have the advantages of digital controllers, they also need time to be replaced by digital controllers. Currently, there are many hydraulic products that use analog controllers or analog-digital hybrid controllers because of the analog circuits' low cost and its inherent advantages.

\subsection{Actuators of Electro-Hydraulic Control Valves}

For hydraulic systems, the electro-hydraulic control valve is a signal conversion and power amplifying component [26], and its power amplification factor reaches 104-106 with a fast response speed. In 1946, Tinsley of the United Kingdom applied for a patent for a two-stage electro-hydraulic control servo valve, whose pilot stage of the servo valve consisted of an electromagnet-driven spool valve [27]. The torque motor invented by the MIT Dynamic Analysis and Control Laboratory in the 1950s has significantly improved servo valve technology. Since then, Moog, Rexroth, and other hydraulic component manufacturers have introduced single flapper-nozzle valves, dual flapper-nozzle valves, jet-pipe servo valves, and other products. As a result, electro-hydraulic servo valves are used in aerospace, military defense applications, industry, automation, and a wide variety of other fields [28], as demonstrated in Figure 6(a) and (b). The spool and sleeve of the servo valve need to be precisely matched, which makes it costly to manufacture. The pilot hydraulic bridge can be achieved by creating a fine hole for the flow path, which requires high oil cleanliness.

Therefore, in the late 1960s, electro-hydraulic proportional valves with proportional electromagnets as electro-mechanical converters were developed, which

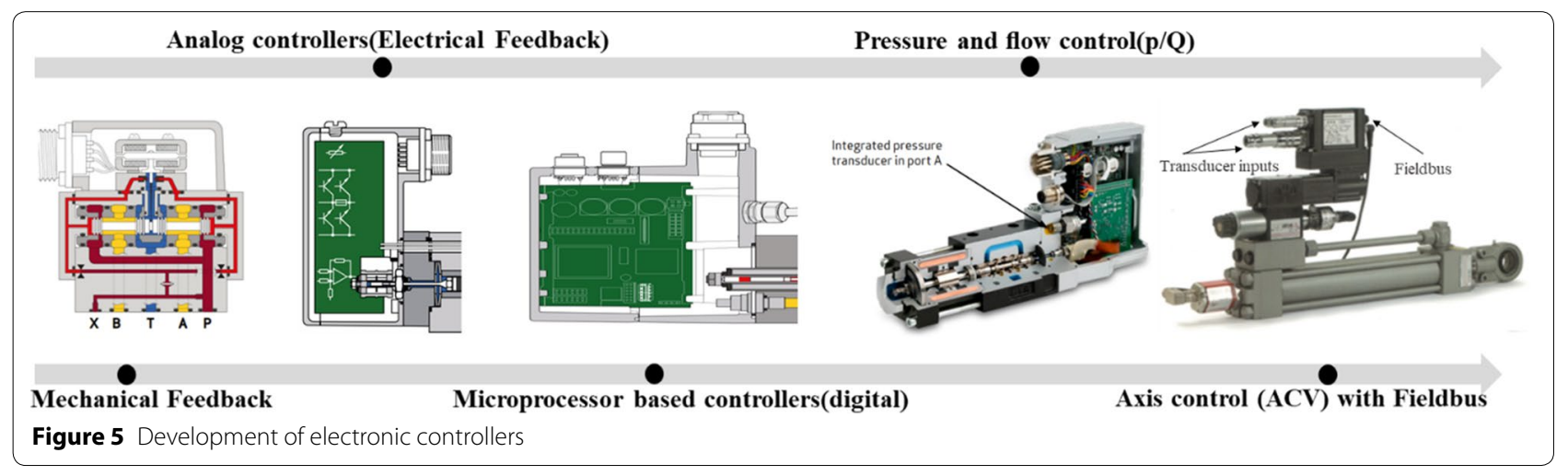




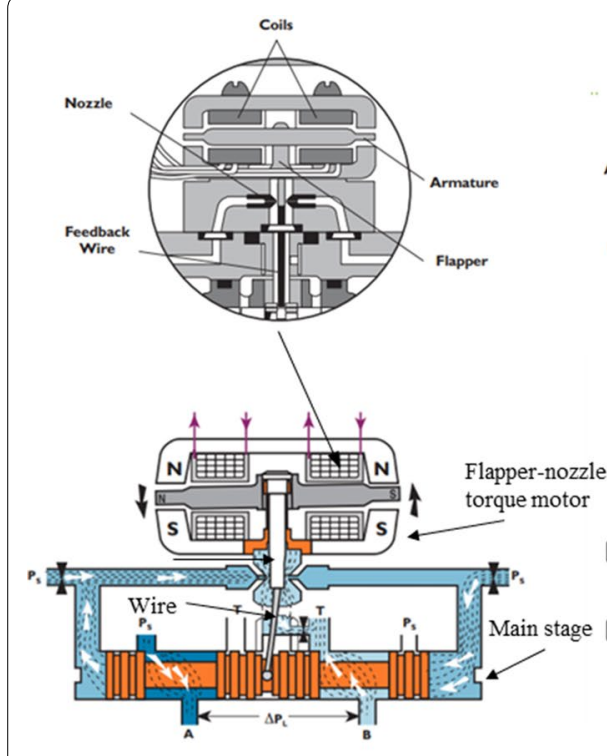

a

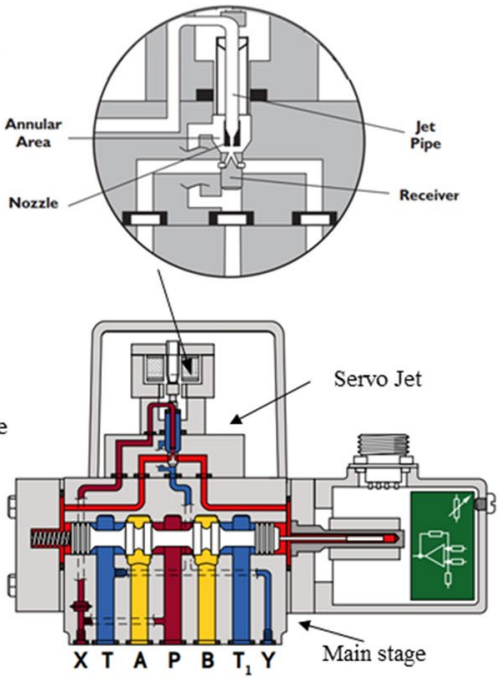

b

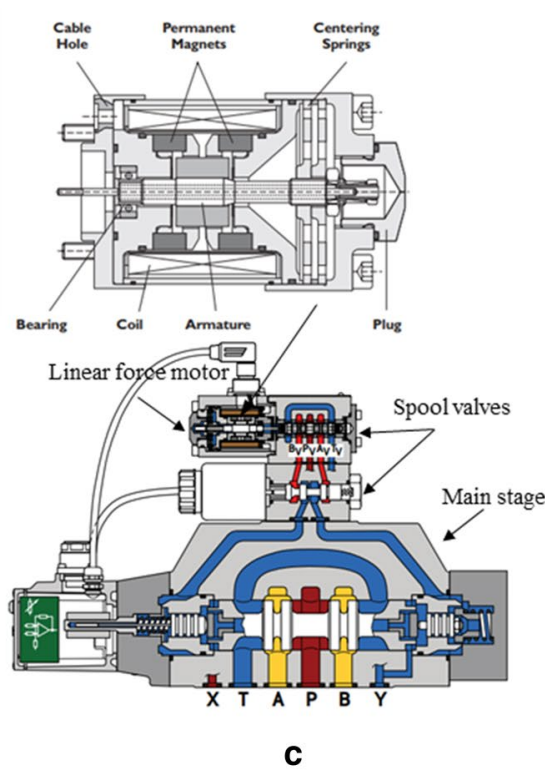

C

Figure 6 Multi-stage valves and pilot stages'actuators: (a) Flapper-nozzle pilot stage; (b) Servo jet pilot stage; (c) Spool valve pilot stage

are more robust. The price is low and the cleanliness of the oil is not high $[29,30]$. Multi-stage valves in which the pilot stages and the main stage are both spool valves in Figure 6(c) are currently used in a variety of fields. Electro-hydraulic proportional valves enabled with zero laps are also called proportional servo valves with a relatively high-frequency responsiveness. The valve opening is proportional to the continuous input signal. The difference between them is reflected in the performance and structure [20].

Although torque motors and electromagnetic solenoid actuators are very common converters, new electronic mechanical converters of valves are constantly coming out. There are many kinds of electronic mechanical converters that are used in electro-hydraulic control valves, as presented in Figure 7 . With the exception of electro-hydraulic proportion valves, some electro-hydraulic control valves use the rotary form, which is called the rotary valve [31,32]. Bath University's Min Pan et al. have used high-speed rotary valves to control the flow and pressure of a hydraulic supply [33]. Actuators made from piezoelectric materials [34-37], magnetostrictive materials [38-40], or shape memory alloys $[41,42]$ provide different ideas for valve actuators. Nevertheless, novel form actuators designed by voice coil actuators $[43,44]$, a stepping motor $[45,46]$, and magnetorheological (MR) fluid [47] are booming with the development of Industry 4.0 [1]. Christophe Habegger et al. developed a new generation of electromechanic valve actuation technology with brushless digital current (BLDC) motors [46].
Since there are a variety of electric actuators, electrohydraulic control valves show better driving characteristics and various forms for different applicants with a lower cost and a greater efficiency. The flow rate, pressure, forces, or other system variables can be controlled with different closed-loop feedback signals. The development of electro-hydraulic control valves is the result of the interdisciplinary development of hydraulics, mechanical technology, electronics, materials, controls, and other disciplines, which can contribute to the development of Industry 4.0 [1].

\subsection{Control Strategies and Novel Concept Valves 3.3.1 Control Strategies on Traditional Valves}

Electro-hydraulic control valves used to feature proportional-integral-derivative (PID) controllers; however, many model-based controllers are being developed due to digital technology, which makes an important contribution to Industry 4.0. Because of the PID controller's effectiveness and practicability, it is widely used in electro-hydraulic control valves until now $[48,49]$. In addition, there are also many improvement methods based on PID controllers. Han et al. [35] implemented a fuzzybased PID controller into a piezoelectric actuator-based direct-drive valve. Liu et al. [50] proposed an optimaltuning nonlinear PID controller for hydraulic systems. By adding optimal algorithms like some nonlinear elements, or just feedforward and compensation, the quality of the PID controller can be prompted.

With an improvement in the relative technical requirements for higher controller performance, 


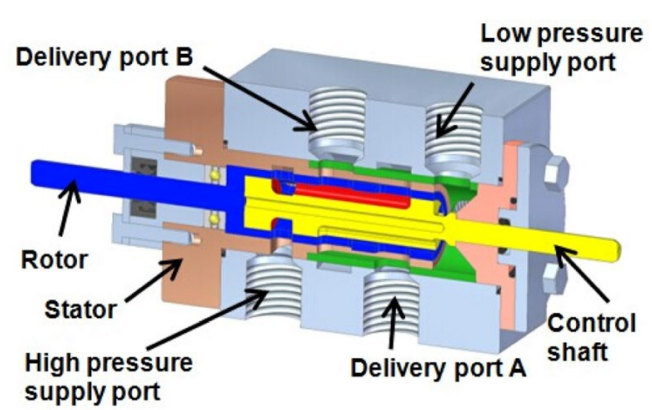

a

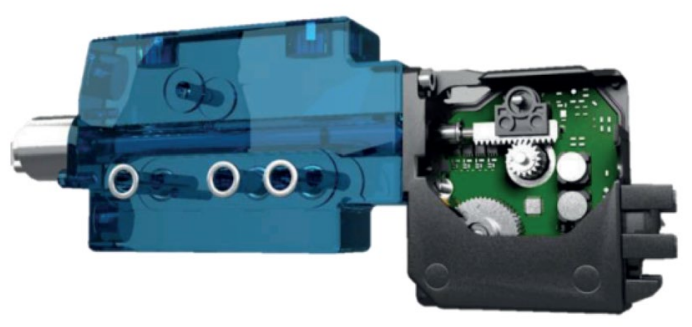

c

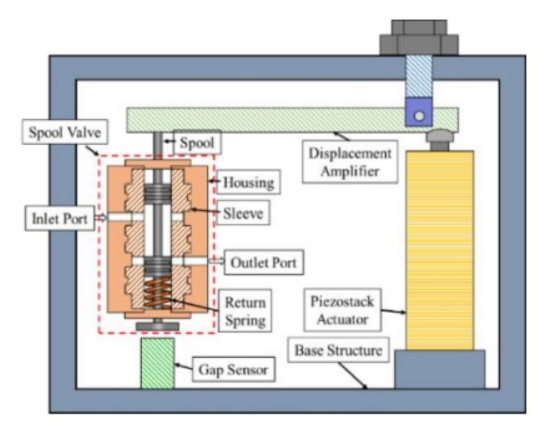

b

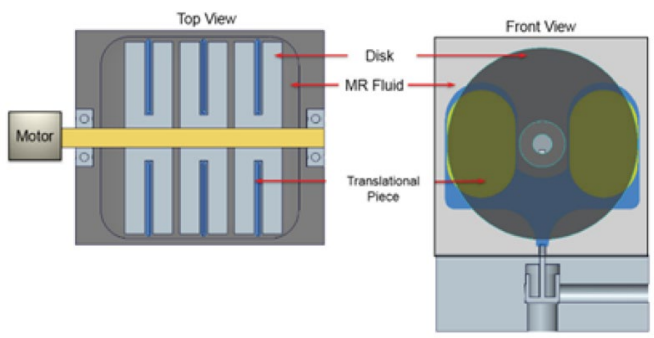

d

Figure 7 (a) Schematic of the rotary valve; (b) Schematic of the piezoelectric actuator valves; (c) Electromechanical valve actuator; (d) Stacked valve configuration of the electronic control valve (ECV)

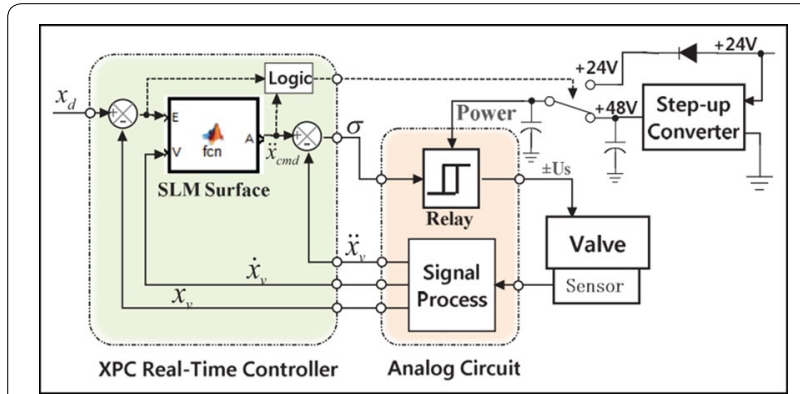

Figure 8 Schematic of the SLM controller with the switch of power supply

studies regarding the electro-hydraulic valves' controller based on a model or process are increasing, especially for digital controllers. Gamble et al. have studied the sliding mode control system and applied it to proportional solenoid valves in comparison to the PID controller [51-53]. Jianhua Wei et al. [54] applied the spatial light modulator (SLM) controller by switching the voltage power supply as depicted in Figure 8 . This also includes an adaptive robust control with flow force compensation to servo-solenoid valves [55] and a controller with a reduced-order extended state observer [56]. Lu et al. [57, 58] studied in detail the dead zone compensation control based on detections of the microflow rate in the pilot stages of the proportional directional valves. The controllers based on the model of the control plants have a feature that they need to know a steady and dynamic characteristic with relative precise parameters for the plant's model. If the parameters are difficult to obtain, the controllers need an adaptive algorithm to ensure its performance [59]. Nevertheless, uncertainty and a disturbance beyond the model should be handled. This includes adding robust terms into the controller [60,61], building a state observer [44], or building a model in which more factors like the flow force and hysteresis phenomenon are considered [62,63]. The Technical University of Cluj-Napoca cooperated with RWTH Aachen University and they proposed an internal model control (IMC) for the servo valves, which increases the impedance of the voice coil motors as shown in Figure 9 [43].

Model-based controllers are more complex than tradition PID; however, they show more potential when dealing with nonlinearity and uncertainty [64]. Since digital controllers are growing in terms of their computing power and control theory development, more controllers and algorithms will be designed and practical applications for Industry 4.0, like the model predictive controller [65] or possibly neural networks [66]. 

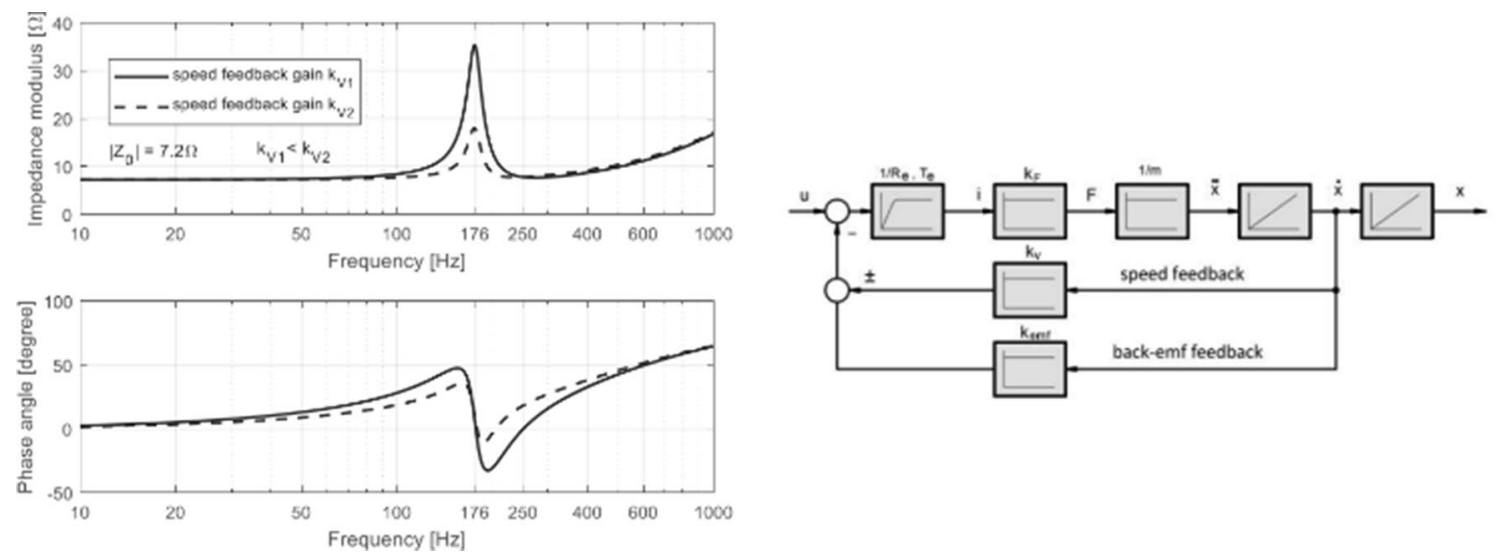

Figure 9 The influence of speed feedback on the equivalent electrical impedance

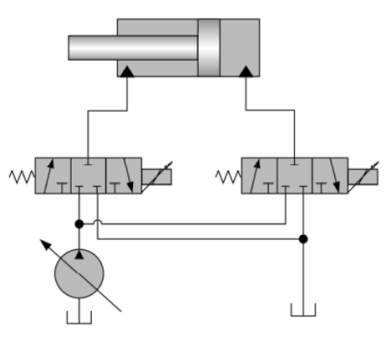

a

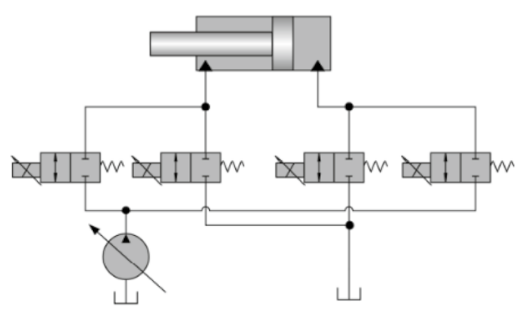

b

Figure 10 Schematic diagram of the independent metering system

\subsubsection{Valves with Separate Meter-in and Meter-out Orifices}

Traditional hydraulic valves like proportional valves link the meter-in and meter-out orifices in one spool to regulate the flow. They are mechanically coupled and bring drawbacks for poor mobility and high energyconsumption, which don't meet the requirements of high efficiency and energy savings for Industry 4.0. For this problem, Professor Jan-Ove Palmberg from Linköping University proposed the concept of separate control for meter-in and meter-out orifices according to Professor Backé's control theory for cartridge valves [67], as shown in Figure 10. The meter-in and meterout valve separately adopts the double valve spools structure to independently adjust its inlet and outlet throttling area, which increases the control freedom of the system and makes it possible to further improve the control and energy-savings performance of the valve. Using three position/three-way electro-hydraulic proportion valves or on/off valves, this replaces the separate orifices that can control the cylinders' speed or force through separately controlling two ends [68], also called an independent metering system (IMS).

Researchers from Aalborg University in Denmark have studied independent control strategies and the influence of the valve structural parameters on the IMS' control performance [69]. At Purdue University, five cone valve combinations were used to study a robust adaptive control strategy for trajectory tracking control and energy-saving control. Among them, four cone valves achieve an independent metering function for the orifices, and one middle cone valve achieves the flow regeneration function [70]. RWTH Aachen University in Germany has also studied various ways of controlling the meter-in and meter-out orifices and they have proposed a single edge meterout control strategy [71]. Zhejiang University designed a novel valve based on the separate orifices concept. This design revealed an impressive improvement of the entire valve performance in which the $-3 \mathrm{~dB}$-frequency of the novel valve improved more than $50 \%$ in comparison to the traditional valve, as shown in Figure 11 [72, 73].

The valves with separate meter-in and meter-out orifices is a good control strategy in the hydraulic field. Compared with the traditional proportional valve control system, it has the potential to improve the energy-saving characteristics of the system and achieve electronic intelligent control. It has a wide variety of applications in the field of excavators, cranes, and other machinery [74]. 
a

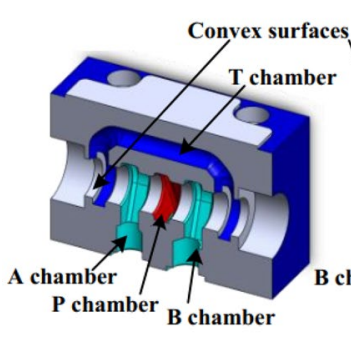

c

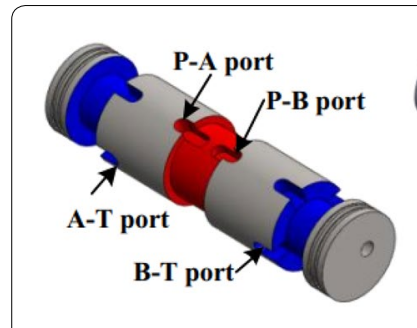

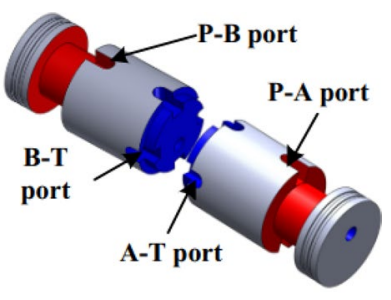

b

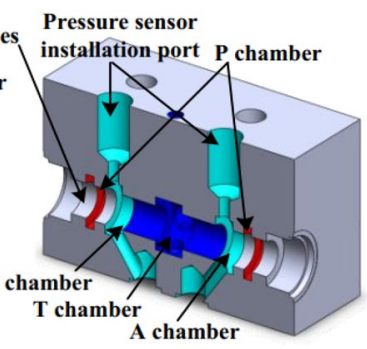

d
Figure 11 Spools: (a) traditional; (b) separate orifices; Housings: (c) traditional; (d) separate orifices

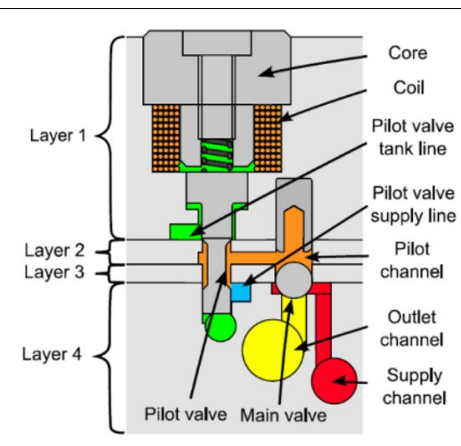

a

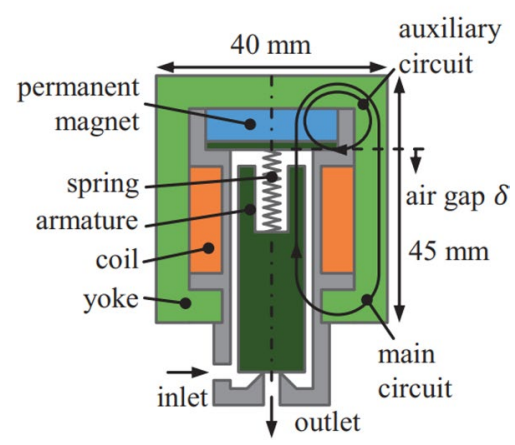

b

Figure 12 (a) A miniature switching valve with the pilot stage; (b) Bi-stable latching valves

on/off main-stage valve that is capable of delivering a flow rate of $9 \mathrm{~L} / \mathrm{min}$ with a response about $1.1 \mathrm{~ms}$, as shown in Figure 12(a). Yang et al. [79, 80] designed a miniaturized digital hydraulic valve along with valve packages. Kramer et al. [6] developed a bi-stable latching valve, which is an energy-efficient alternative to mono-stable switching valves, as presented in Figure 12(b).

Although the on/off valves have a fast response speed, its flow rate is always small. Parallel technology that is based on the on/off valve or switching valve is a solution to that problem, like the digital flow control unit (DFCU) proposed by Linjama as shown in Figure 13(a) [75]. Because each valve group has pulse code modulation (PCM) coding characteristics, the digital hydraulic system also combines IMS [81]. In 2005, Linjama compared the energy efficiency of the digital valve hydraulic system with a traditional proportional load sensitive system and studied the on-line minimization control method of energy loss, which decreased by $36 \%$ [82]. Lantela et al. integrated 32 valves into a valve system to construct $3 / 2$ way switching valves as shown in Figure 13(b), whose flow rate reached $78 \mathrm{~L} / \mathrm{min}$ at 35 bar [83]. Paloniitty et al. [84] also studied the valve package manufacturer along with lamination technology. A low carbon steel plate cut is used that gets punched by an integral press and a laser [77]. Lantela et al. [78] applied a pilot valve to operate an 


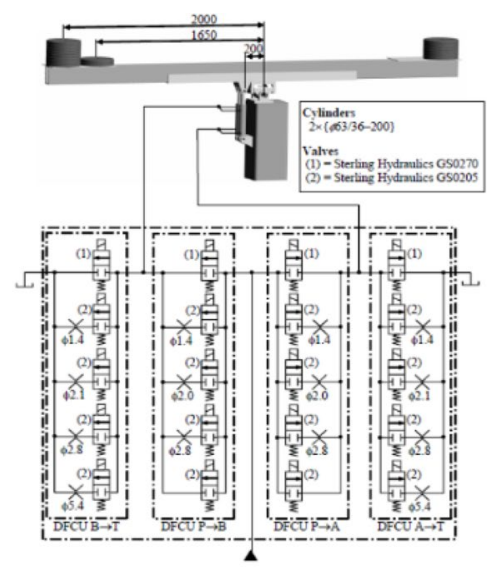

$\mathbf{a}$

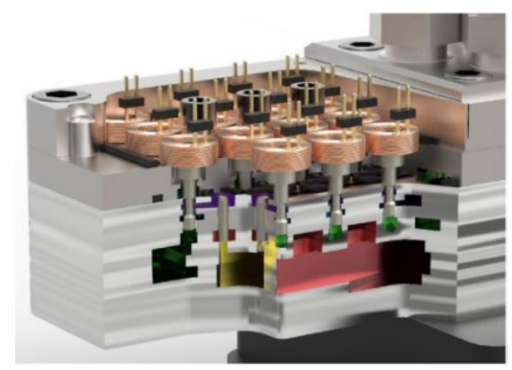

b

Figure 13 (a) Digital hydraulic system with DFCUs; (b) A miniature valve system

cutting machine. Afterwards, welding is performed by copper brazing.

With the application of digital, intelligent, and new materials for 3D printing technology, the hydraulic valve package for digital hydraulic systems can be completed with advanced 3D printing technology by optimizing the flow paths. This will significantly shorten the manufacturing cycle of the valve package, improve the machining accuracy, and help achieve intelligent manufacturing for the digital hydraulic valve package. Digital hydraulics is a qualitative leap for traditional hydraulic systems, which shows a huge potential and market in Industry 4.0.

\section{Manage and Fault Diagnosis}

\subsection{Communication and Human-Machine Interaction}

Modern factories need to build a network of sensing, measurement, and control, which covers the whole production process. Therefore, as an important control component of modern factories, the electro-hydraulic valve also needs to have a measurement function for the pressure, flow, and other signals. Meanwhile, the control function is necessary for quick debugging and integration according to the working conditions, as well as a quick information exchange function for communication through a bus or Ethernet [85].

\subsubsection{Fieldbus-Based Communication Modes}

Fieldbus technology makes the hydraulic valve an independent control element that can achieve decentralized control and centralized management in the industrial field. At the same time, the hydraulic valve and the hydraulic cylinder can form a decentralized independent axis controller by a Fieldbus. The Fieldbus connects the communication unit, which is composed of the electrohydraulic valve and its pressure, flow, and position sensors, with other hydraulic units, electronic units, and central industrial control units to form a data interaction network. This can achieve control of the entire hydraulic system and the collection of basic information.

There are many studies on integrated communication technology for the electro-hydraulic valve. In a study by Keuper et al., there is a hydraulic proportional valve with an embedded electronic controller. This is applied in agriculture, which achieves the transmission of position data for the valve spool through the controller area network bus (CAN bus) [86]. Tapio Virvalo et al. of the Tampere University of Technology in Finland applied the CAN bus technology into a proportional servo valve. Controlling the communication structure of the system connected by the CAN bus is illustrated in Figure 14. An intelligent two-wire valve based on the power line carrier and the CEBUS Fieldbus has been designed, simulated, and tested by Li Weibo of Zhejiang University. This verified the feasibility and the advantages of Fieldbus technology in the field of hydraulic valves [87].

With the process of digitalization in the hydraulic industry, there is a growing demand for a remote monitoring capability of electro-hydraulic valves. Many enterprises have released a series of hydraulic valves with a communication interface. Most of those valves equip Fieldbus interfaces since they have a huge application market and mature hardware technology. ATOS DLHZO-TEZ series valves and MOOG D636 provide CAN, Profibus DP, EtherCAT interface for users to choose from. HYDAC P4WERE06 integrates the LIN interface. Parker D1FC integrates EtherCAT. Some other control blocks, like HAWE PSL series, Danfoss PVG series, Eaton CMA200, integrate the CAN bus interface.

\subsubsection{Bluetooth-Based Communication Modes}

In some industrial scenes, where the electro-hydraulic valves do not have enough place for communication cables, it is necessary to make the communication networks wireless. On the other hand, wireless communication networks can make it convenient for engineers to debug these valves and to monitor the equipment states. 


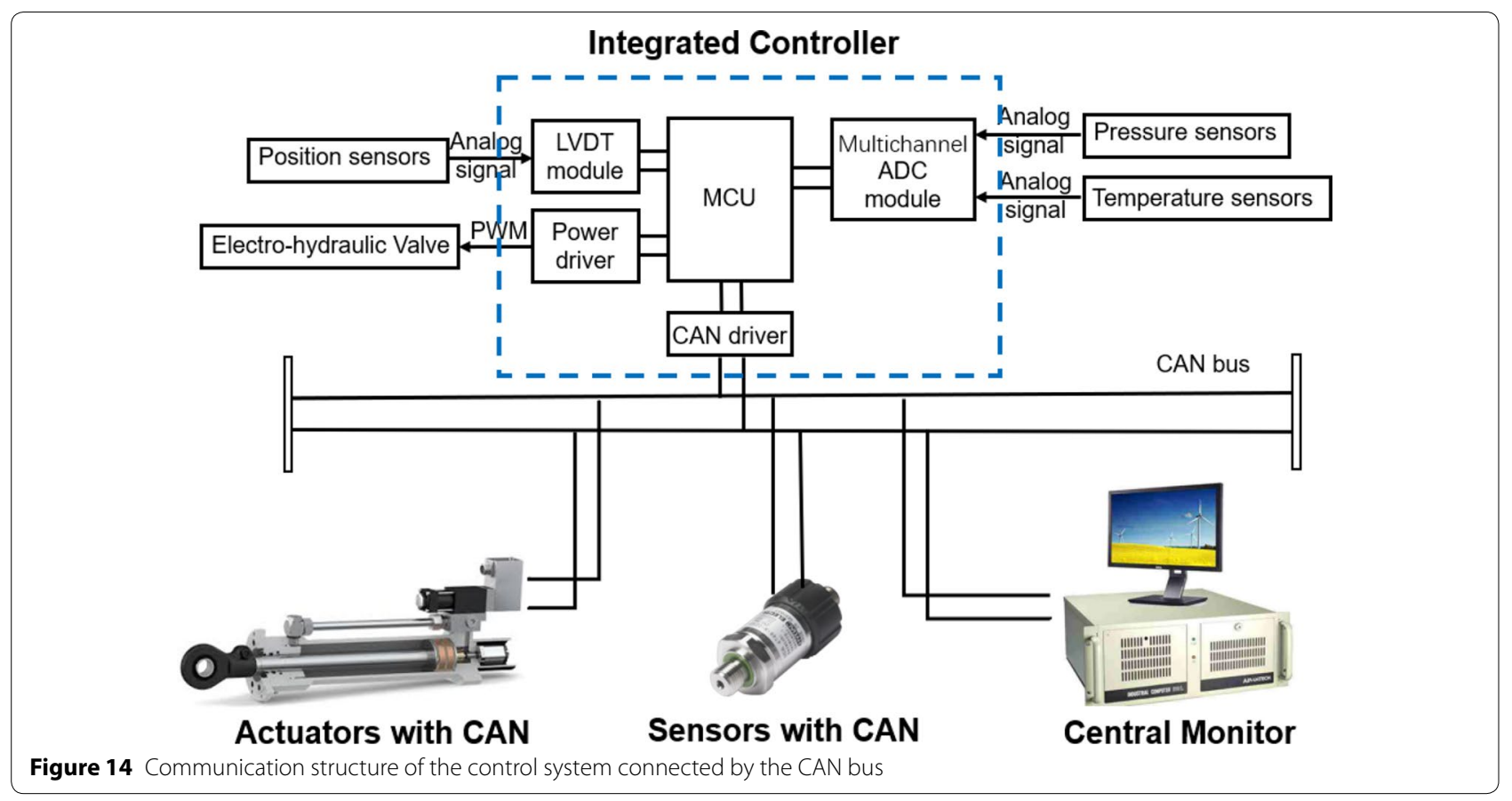

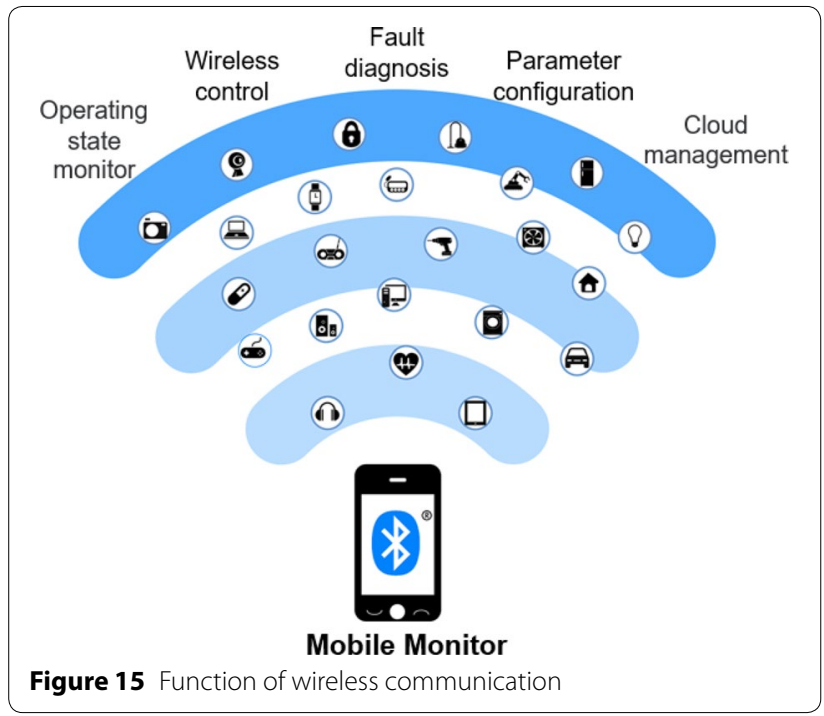

In regard to the demand for wireless communication networks, some enterprises have released products that are integrated with Bluetooth. SUN 7904A24, a proportional cartridge valve, integrates Bluetooth. HAWE RV2S-BT integrates Bluetooth, which makes valves convenient and intelligent to control, monitor and manage. Figure 15 shows what wireless communication can do.

\subsubsection{IO-Link-Based Communication Modes}

There are lots of Fieldbus standards in different industries, which makes it a huge challenge for users to connect with sensors, actuators, and valves with different communication interfaces in a project. A communication interface called IO-Link can solve this problem. IO-Link is an open standard so that products that are integrated with IO-Link can almost connect with any equipment with a different Fieldbus. This advantage makes it easier for these products to combine with other pieces of equipment that has an independent control system. However, it can only achieve point-to-point communication, and it cannot combine multiple devices into one communication network without the IO-Link Master or the IO-Link Hub. Rexroth 4WRPEH is a product that is integrated with IO-Link.

\subsubsection{Human-Machine Interaction Software}

As a hardware basis, those interfaces can build a huge communication network. However, what makes it incredible is the software behind the network. We can control, monitor, and manage those valves remotely and in real-time using PC software, such as ATOS Z-SW, Parker ProPxD, MOOG Valve, and Pump Configuration Software. At the same time, some valve faults, such as communication errors, hardware errors, and overloading the overloading the power supply voltage, can be diagnosed remotely by that software. Some other applications are designed for those mobile devices, such as SUN AmpSet Blue and HAWE eControl. 


\subsection{Intelligent Fault Diagnosis}

Equipment must be designed so that it is safe, reliable, and of high quality [88]. The EU issued and implemented the Machinery Safety Directive 2006/42/EC. With the development of statistical mathematical tools, the reliability and life of hydraulic products can be calculated quantitatively by using mathematical tools. In addition, the evaluation criteria are more specific. Internationally famous manufacturers have started to carry out product reliability tests and fault diagnosis. Most products in the current market focus on diagnosing some simple faults for electro-hydraulic valves, such as electrical and communication failures. In the application scenario, valves often meet some internal deep faults, which cannot be detected by an existing sensor network.

\subsubsection{Common Faults of Electro-Hydraulic Valves}

Marco Münchhof built a specialized experiment rig for faults diagnosis for a valve-controlled cylinder system [89]. Figure 16 shows the result of his experiment and which faults will often occur in different elements of the valve-controlled cylinder system. The proportion of each component fault in the system is shown in Figure 17(a). As can be seen from Figure 17(a), in the valve-controlled cylinder system, the fault of the valve spool and the valve body accounts for $51 \%$. Therefore, Münchhof further
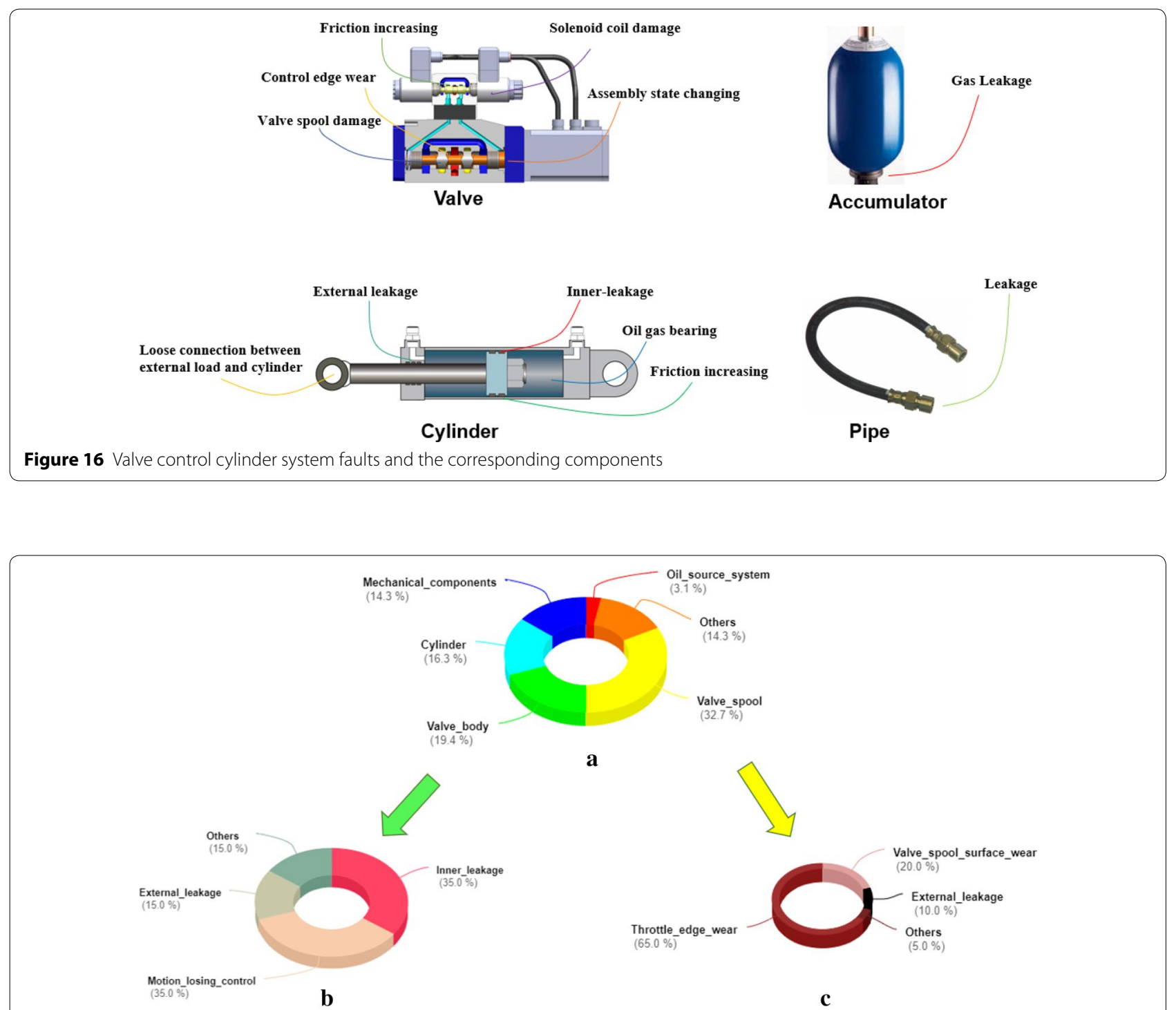

Figure 17 (a) The proportion of each element failure; (b) The proportion of the valve body faults; (c) The proportion of the valve spool faults 
summarized the fault of the valve body and the valve spool as illustrated in Figure 17(b) and (c).

Denson Hydraulic has provided the literature with some common failures for the proportional directional valve in engineering practice and their causes as shown in Figure 18 [90].

From these figures above, a conclusion can be drawn that many faults occur in engineering practice because of the system design and personal operation errors. At the same time, we cannot monitor the movement state and the system operation state of the valve without suitable measuring devices so that the fault can only be detected when the fault is obvious. Hence, studies on intelligent fault diagnosis of the valve are vital to find the fault in time and to prevent the system from losing control. Therefore, the focus of fault diagnosis is how to extract the fault features from multi-sensor signals and to judge the abnormal state. According to the theory and methods of fault diagnosis, the common methods in the field of the hydraulic systems can be divided into two categories: a data-based diagnosis method and a model-based diagnosis method [91]. Figure 19 shows the common methods in the fault diagnosis of the electro-hydraulic valve.

\subsubsection{Data-Based Fault Diagnosis Methods}

The data-based fault diagnosis method mines the hidden information in the data through various data analysis methods to predict the faults; however, the acquisition cost of vast data is high, and the uncertainty and incompleteness of the data will affect the accuracy of this method. In terms of practical applications, it is in realtime and it is a practical method to detect a signal threshold to diagnose the faults. Some electro-hydraulic valve products, like Eaton AxisPro, install sensors in the valve to improve the state acquisition ability, and it also uses

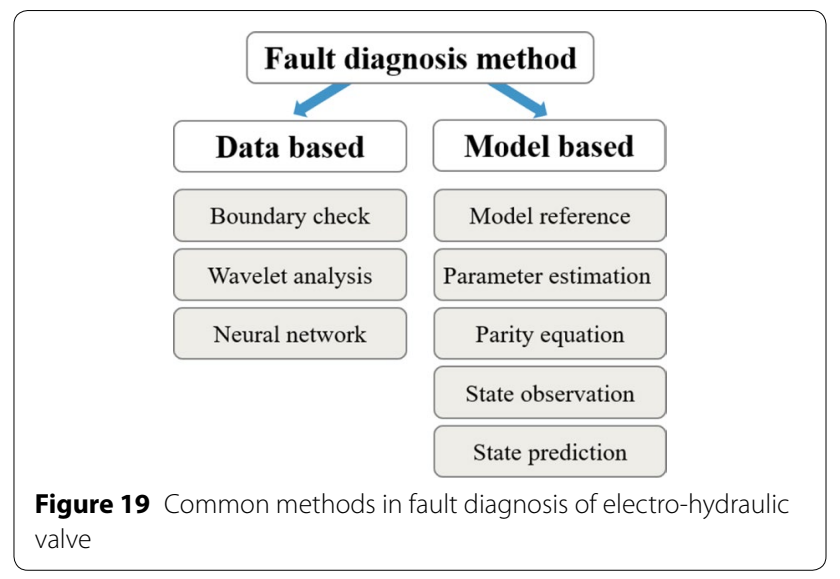

the numerical threshold to monitor the operation states of the valve. Afterwards, the state quantities of the valve are checked to see if they exceed the preset threshold value to diagnose the faults.

This method has been extended by Raduenz et al. According to a large number of collected data, the threshold range of the fault diagnosis has been effectively reduced [92, 93]. For a specific proportional valve, the relationship between the control signal and the displacement of the valve spool changes in a certain range with the change of the working conditions. If the fault occurs, the corresponding relationship will change. When the same control signal is given, the actuator or valve spool displacement will exceed the specified threshold value, which can be used for fault diagnosis.

Because the electro-hydraulic valve usually works in a relatively stable state and there is less effective highfrequency information in the signal, many researchers have chosen the signal during the step response of the valve spool as the reference signal. For example, Sharifi

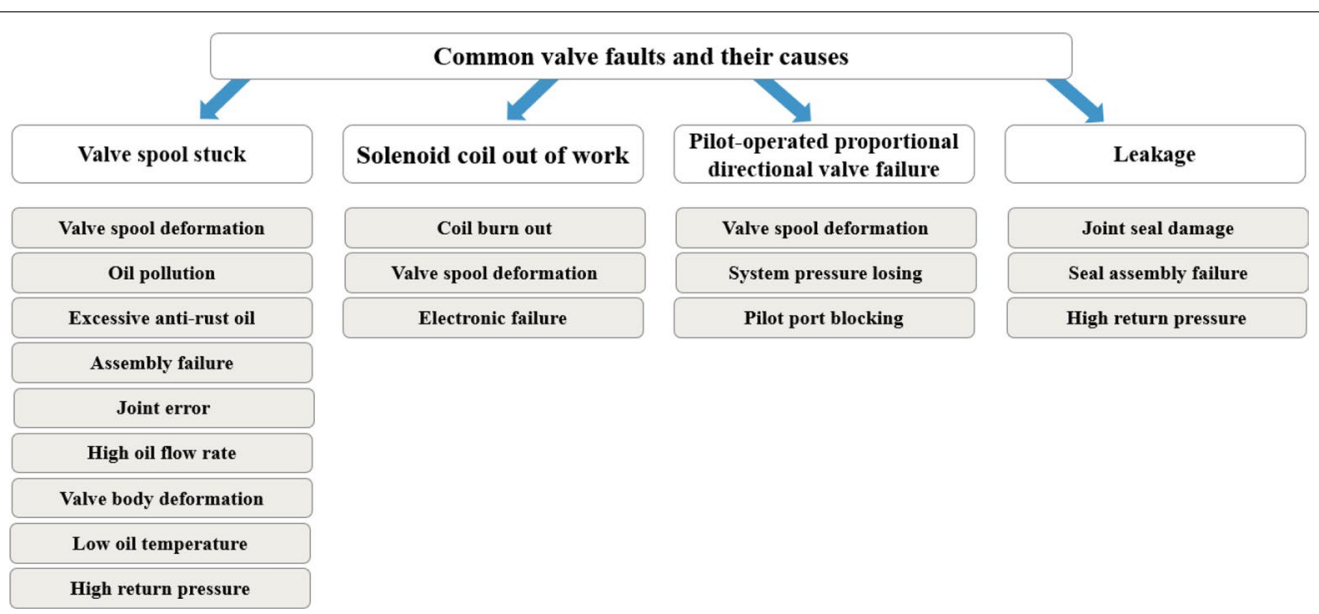

Figure 18 Common valve faults and their causes 
extracted the step amplitude, the peak generation time, and the oscillation time in the pressure step curve generated by the system during the step process of the valve spool. The features under the normal working conditions and the leakage working conditions were analyzed in clusters through the neural network to identify the leakage fault, as depicted in Figure 20 [94, 95]. In addition, the error of the fault identification is $30.2 \%$.

In order to increase the fault information and improve the sensitivity of the fault diagnosis, Zhao et al. [96] and Chao [97] adopted the method of wavelet packet signal decomposition to process the pressure signal and use the energy distribution for each level of the wavelet to diagnose the leakage fault. Wang et al. [98] further combined the wavelet packet signal decomposition method with the feature data principal component analysis method while adding the fault features with the feature data extracted from the characteristic curve to facilitate rapid fault diagnosis.

The lack of sensor information still severely limits the fault diagnosis ability for the method mentioned above. Therefore, on the basis of adding sensors, the state information collected by the pressure sensor and displacement sensor was integrated to establish the corresponding relationship between the fault phenomenon and the fault signal. In addition, the fault was diagnosed by calculating the membership degree [99]. At the same time, many researchers [100-105] have used the neural network or similar methods to link the valve characteristic curve and fault in case of failure to avoid the problem of manually finding the signal characteristics.

However, the above methods can easily be affected by the characteristics of the training data and they need a large amount of data to support the training process. To make up for the above shortcomings, some researchers use the neural network to establish the hydraulic system model and take the calculated deviation as the fault diagnosis basis [106]. This method reduces the requirement of the training data and the fault features contain more physical information, which is easy to understand and further modify. For example, Liu et al. [107] proposed a two-stage RBF (radial basis function) neural network as the fault diagnosis method, which is shown in Figure 21.

Liu et al. [108, 109] improved the algorithm by using support vector machine regression (SVR) and the Elman neural network, which reduced the demand of the algorithm for data volume and avoided the risk of falling into a local minimum. Hu et al. [110, 111] and Cao et al. [112] also used the support vector machine (SVM) method to build the hydraulic system model. They also used the composite method to judge the deviation, which gets better diagnosis results in the case of small training samples.

From the methods listed above, it can be seen that the data-based fault diagnosis method has great flexibility because it uses a large amount of data to summarize the rules. By changing the method, the fault diagnosis can be achieved in different situations from a few sensors to a large number of sensors. However, because the electrohydraulic valve and the hydraulic system are complex and

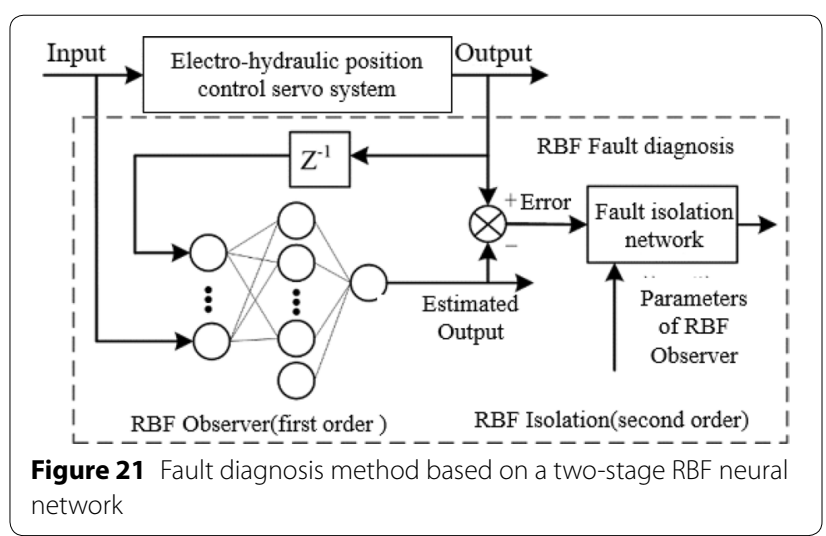

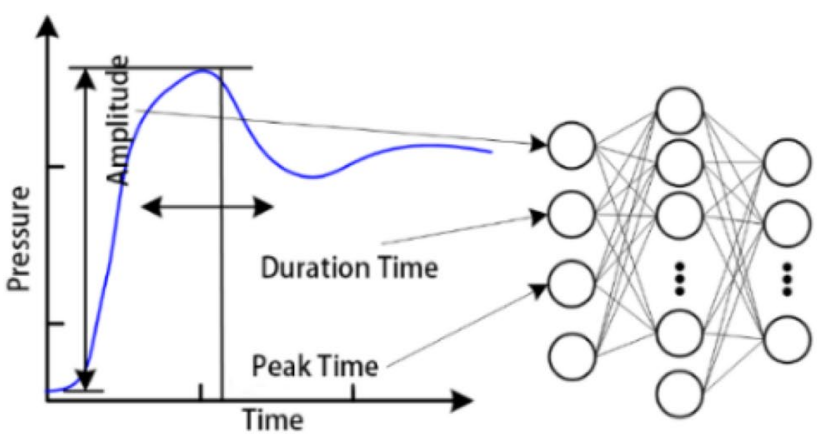

Feature Extraction Netural Network Training

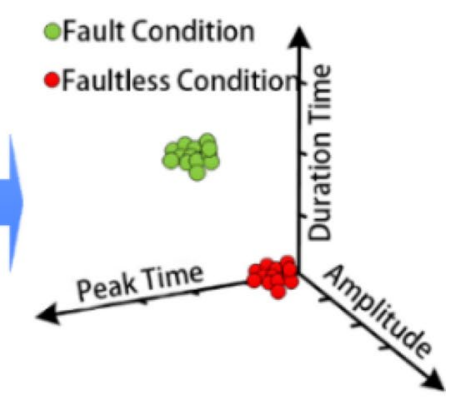

Clustering Analysis

Figure 20 Fault feature selection and the clustering schematic diagram [94, 95] 
nonlinear, they have a variety of fault forms and a large amount of data is required for model training. Because the hydraulic system is often used in the heavy load situation, lots of simulation works will consume too much energy and time, which increases the difficulty of using data-based fault diagnosis methods.

\subsubsection{Model-Based Fault Diagnosis Methods}

The model-based fault diagnosis method closely connects the fault characteristics with the model parameters; however, it is difficult to build an accurate mathematical model. Because the model has been validated by a lot of data, more accurate calculation results can be obtained. At the same time, the physical model is used to calculate the internal state of the system, which effectively reduces the requirements of the model correction data. Figure 22 provides an illustration of how it works.

In order to improve the accuracy of the model of the electro-hydraulic valve control cylinder system, Münchhof [89] used the least squares method. Even though the model is compensated in real-time, the fault diagnosis can be carried out by comparing the identified parameters with the parameters under normal working conditions [113]. Samadani et al. [114] also used the method of parameter estimation to identify the amplification coefficient of the electromagnetic force and the friction force of the valve spool movement in the electro-hydraulic servo valve. Another direct method is to directly use the open-loop model simulation to compare with the actual physical system signal and diagnose the fault through the obtained deviation [115-118]. Due to the lack of a mathematical mechanism to ensure the unbiasedness of the model, this method needs to use a more complex

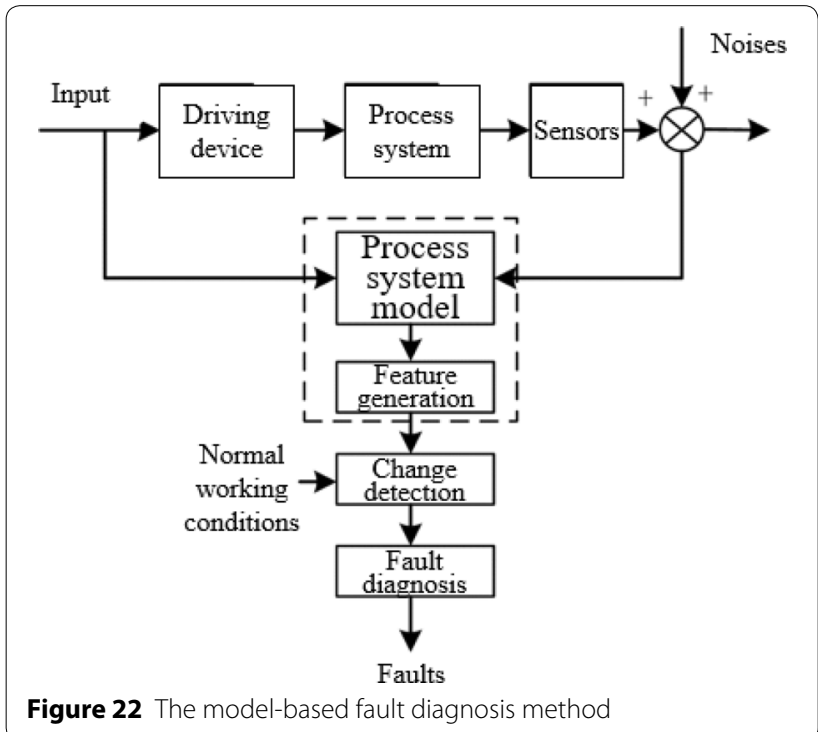

nonlinear model in the modeling process. In addition, more data is required to correct the model.

The parity space-based fault diagnosis method also uses the open-loop model to calculate the deviation signal. This method mainly uses historical data to establish the transfer equation. Although there is no acquisition signal to correct the model, the use of historical data improves the accuracy of the model. Münchhof [89] studied the fault diagnosis of the proportional servo control system with this method and the effectiveness of this method is verified for a variety of fault diagnoses.

In order to avoid the influence of the modeling-error for the open-loop model on fault diagnosis, most of the existing model-based fault diagnosis methods use the theoretical unbiased model as the contrast model to compensate for the model error. The common methods are the state observer and the state predictor.

In 1964, Luenberger proposed an observer for linear systems, which became an important method for state estimation and fault diagnosis [119]. Min et al. [120] used a linear output observer to calculate the system deviation and diagnosed the abnormal response fault of the servo valve. Abou et al. [121] also used the linearization method to model the hydraulic system and set up the fuzzy fault diagnosis rules to diagnose the severity of the fault. Because a linear model produces the system error, the observer can design methods while considering the modeling error and the external interference, which has attracted the attention of researchers.

The first way to reduce the influence of the modeling error is to perfect the model and reduce the modeling error. Khan et al. [122] designed the feedback gain of an observer based on data and built a nonlinear observer to obtain the system deviation and diagnose the faults such as the change in the oil's elastic modulus. Rezazadeh et al. [123] also used a similar method to diagnose the leakage in the electro-hydraulic proportional system.

The second way is to decouple the unknown factor and the known response law by feedback using the designed observer. Qiaoning Xu decoupled the interference term, which includes damping and the external load, along with the target input and the output feedback. This distinguishes the fault performance from the influence of unknown parameters $[124,125]$.

The third way is to use robust control algorithms, which uses feedback data to compensate for the model error and to improve the overall tracking performance of the model. Yao et al. $[126,127]$ proposed an adaptive robust observer design method based on the nonlinear coordinate transformation and an indirect adaptive strategy. Yao et al. [128] also proposed a state reconstruction method for nonlinear systems. Gayaka et al. [129] combined identification with the online diagnosis method as 


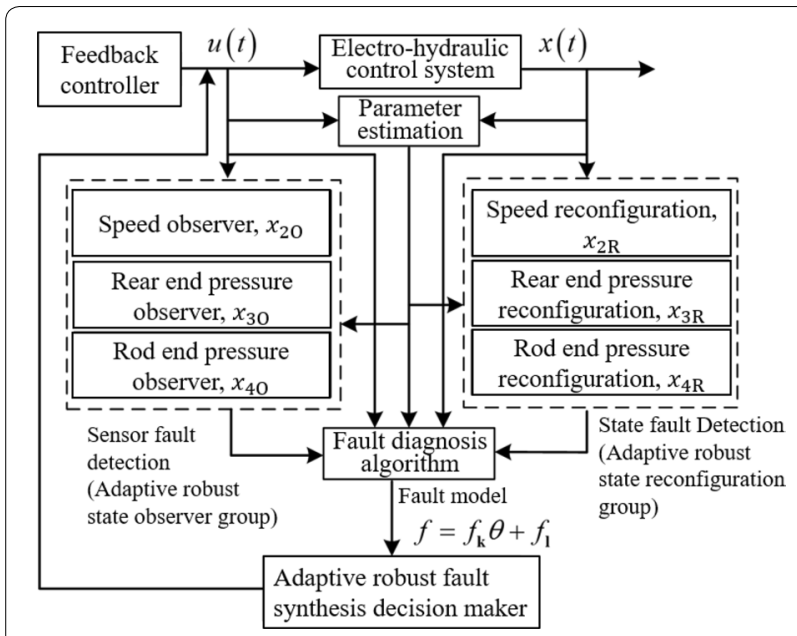

Figure 23 Fault diagnosis method based on the robust observer and the state reconstruction

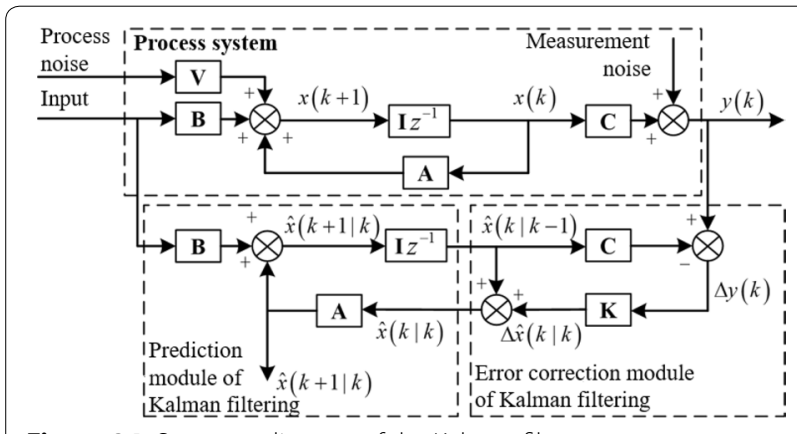

Figure 24 Structure diagram of the Kalman filter

shown in Figure 23. In addition, Alwi et al. [130] and Liu [131] used a sliding mode observer to diagnose the valve failure in the electro-hydraulic servo system.

The method based on the state predictor mainly refers to the fault diagnosis method based on the recursive Bayesian filter algorithm, and the Kalman filter is a typical implementation form of the recursive Bayesian method. The basic structure of the Kalman filter is shown in Figure 24. Because the electro-hydraulic valve and its system are typical nonlinear systems, the application of a nonlinear Kalman filter for the fault diagnosis of electrohydraulic directional valves has been introduced.

The state prediction of the nonlinear Kalman filter can be solved as the product of the nonlinear function and the Gaussian probability density function [132]; hence, the discrete Kalman filter method is mainly developed from two aspects: the approximation of the nonlinear function and the approximation of the Gaussian probability density function [133]. Wang et al. [134] used EKF (Extended Kalman Filter) to study the liquid elastic fault.
Pulak Halder's team used EKF with different acquisition signals for feedback during comprehensive fault diagnosis; this was mainly used for the diagnosis of sensor failure and leakage $[135,136]$. An and Sepehri used EKF to segment the friction force, which has a good effect on the early diagnosis of leakage [137-139]. Due to the serious linearization error introduced by EKF, the flexibility of the application is limited.

The approach method to a Gaussian probability density function is a typical unscented Kalman filter method, which can improve the accuracy of the model $[140,141]$. Sepasi et al. [142] used the mean absolute error of the pressure and displacement signals of the two chambers of the cylinder as the signal characteristics. This can obtain better fault diagnosis results for the valve port flow coefficient changes and other faults.

Nurmi and Mattila [143] studied the application of the UKF (Unscented Kalman Filter) algorithm in the fault diagnosis of the swing cylinder system, which is controlled by the four-position three-way proportional directional valve. The experimental results show that the proposed UKF fault diagnosis method can effectively diagnose the leakage even when the leakage flow is only $5 \%$ of the valve port flow. Nurmi and Mattila [144] extended the fault diagnosis method to the pilot proportional directional multi-valve cylinder control system with proportional reducing valves as the pilot stage in their later research. Experiments show that the UKF fault diagnosis method and adaptive threshold method can effectively avoid the impact of the impact signal on the fault diagnosis and achieve the detection of the small amplitude fault.

The communication interface that steps toward integration and compatibility makes the valve a component that has self-sensing, self-diagnosing, and IoT information interaction capabilities. Fault diagnosis is an important part of modern intelligent valves that are oriented to Industry 4.0. This can reduce the chance of an accident and is the basis for predicting the life of the valve. The combination of data-based and model-based methods will make the fault diagnosis process more accurate and efficient.

\section{Conclusions}

Electro-hydraulic control valves experienced a longtime development from a pure mechanical structure to mechatronics hydraulics integration. In addition, electrohydraulic control valves are currently being integrated with digital technology and a variety of communication technologies. Since Industry 4.0 is an ongoing revolution, electro-hydraulic control valves should show its vitality with new technology. The valves oriented to Industry 4.0 can be intelligent with the abilities to acquire state 
information, monitor and perform diagnoses online, and provide more efficient control.

This paper reviewed the electro-hydraulic control valves' hardware development with respect to its sensors, actuators, and electronic controllers. High precision integrated sensors and powerful computing digital controllers could be trending in the future. Accurate modeling and experimental curve fitting methods have achieved good results for indirect state perception. With the addition of new technologies like neural networks, the accuracy and computational complexity of indirect status acquisition methods have been improved. In the meantime, digital controllers were discussed, which shows the potential of adaptive and robust controllers. Furthermore, the digital hydraulic was investigated with the independent metering system and on/off valves, which is an important direction for industrial applications due to its discrete properties. Then, electro-hydraulic valves with integrated communication interfaces like Fieldbus, Bluetooth, and IO-Link build the hardware foundation for the hydraulic Internet of Things and then transmit the visual state of valves to users through software. Finally, data-based and model-based fault diagnosis methods allow the inner faults of electro-hydraulic valves to be diagnosed in real-time. Electro-hydraulic control valves can become digital, integrated, and intelligent; thus, promoting the progress of the whole hydraulic industry close to Industry 4.0. Electro-hydraulic control valves still have many challenges to overcome, which is of great significance for the future of hydraulic technologies.

\section{Acknowledgements}

Not applicable.

\section{Authors' Contributions}

BX determined the overall framework and central idea of the article; JS and SL wrote the manuscript; QS helped to collect and organize materials and JZ checked and approved the manuscript. All authors read and approved the final manuscript.

\section{Authors' Information \\ Bing Xu, born in 1971, is currently a Professor and a Doctoral Tutor at School of Mechanical Engineering, Zhejiang University, China where he is currently the Deputy Director of the State Key Laboratory of Fluid Power and Mechatronic Systems. He received his Ph.D. degree in fluid power transmission and control from Zhejiang University, China, in 2001. His research interests include fluid power components and systems, mechatronics systems design, energy-sav- ing, and motion control for mobile machinery. Tel: +86-571-87952500.}

Jun Shen, born in 1995, is currently a Ph.D. candidate at State Key Laboratory of Fluid Power and Mechatronic Systems, Zhejiang University, China. He received his bachelor degree from Wuhan University, China, in 2018. His research interests include electro-hydraulic control technology and intelligent hydraulic components and systems.

Shihao Liu, born in 1997, is currently a Ph.D. candidate at State Key Laboratory of Fluid Power and Mechatronics System, Zhejiang University, China. He received his bachelor degree from Zhejiang University, China, in 2019. His research interests include fault diagnosis of electro-hydraulic valves.
Qi Su, born in 1987, is currently a postdoc at State Key Laboratory of Fluid Power and Mechatronic Systems, Zhejiang University, China. He received his Ph.D. at Zhejiang University, China, in 2016.

Junhui Zhang, born in 1983, is currently an Associate Research Fellow at State Key Laboratory of Fluid Power and Mechatronic Systems, Zhejiang University, China. He received his Ph.D. degree in fluid power transmission and control from Zhejiang University, China, in 2012. His research interests include noise reduction of hydraulic pumps, fluid power components and systems, and mechatronic systems design.

\section{Funding}

Supported by NSFC-Zhejiang Joint Fund (Grant No. U1509204), and National Natural Science Foundation of China (Grant Nos. 51835009, 51922093).

\section{Competing Interests}

The authors declare no competing financial interests.

Received: 4 December 2019 Revised: 20 March 2020 Accepted: 23 March 2020

Published online: 01 April 2020

\section{References}

[1] H Kagermann, W Lukas, W Wahlster. Industrie 4.0: Mit dem Internet der Dinge auf dem Weg zur 4. industriellen Revolution. VDI Nachrichten, 2011, 13(11): 2 .

[2] M F Rahman, N C Cheung, KW Lim. Position estimation in solenoid actuators. IEEE Transactions on Industry Applications, 1996, 32(3): 552-559.

[3] A C Yudell, J D Van de Ven. Predicting solenoid valve spool displacement through current analysis. International Journal of Fluid Power, Taylor \& Francis, 2015, 16(3): 133-140.

[4] P Proost. Sensorless position estimation on a proportional electrically adjustable hydraulic valve. Ghent: Ghent University, 2015.

[5] T Braun, J Reuter, J Rudolph. Position observation for proportional solenoid valves by signal injection. IFAC-PapersOnLine, 2016, 49(21): 74-79.

[6] T Kramer, J Weber, G Pflug, et al. Smart realisation of energy savings during switching operation at bi-stable process valves. Actuator 2018; 16th International Conference on New Actuators, 2018: 1-4.

[7] H E Merritt. Hydraulic control systems. John Wiley \& Sons, 1991.

[8] D Wu, R Burton, G Schoenau. An empirical discharge coefficient model for orifice flow. International Journal of Fluid Power, 2002, 3(3): 13-19.

[9] D Wu, R Burton, G Schoenau, et al. Modelling of orifice flow rate at very small openings. International Journal of Fluid Power, 2003, 4(1): 31-39.

[10] J Dobchuk, R Burton, P Nikiforuk. A modified turbulent orifice equation approach for modelling valves of unknown configuration. International Journal of Fluid Power, 2007, 8(3): 25-30.

[11] J R Valdes, J M Rodriguez, J Saumell, et al. A methodology for the parametric modelling of the flow coefficients and flow rate in hydraulic valves. Energy Conversion and Management, 2014, 88: 598-611.

[12] S Dimitrov, S Simeonov, S Cvetkov. Static characteristics of the orifices in a pilot operated pressure relief valve. Hydraulica, Magazine of Hydraulics, Pneumatics, Tribology, Ecology, Sensorics, Mechatronics, 2015(2/2015): 34-38.

[13] J Das, S K Mishra, R Paswan, et al. Characterization and tracking control of a nonlinear electrohydraulic valve-cylinder system. Proceedings of the Institution of Mechanical Engineers, Part E: Journal of Process Mechanical Engineering, 2016, 230(5): 371-384.

[14] M Borghi, M Milani, R Paoluzzi. Influence of notch shape and number of notches on the metering characteristics of hydraulic spool valves. International Journal of Fluid Power, 2005, 6(2): 5-18.

[15] R Åman, H Handroos, T Eskola. Computationally efficient two-regime flow orifice model for real-time simulation. Simulation Modelling Practice and Theory, 2008, 16(8): 945-961.

[16] B Xu, J Ma, J Lin. Computational flow rate feedback and control method in hydraulic elevators. Chinese Journal of Mechanical Engineering, 2005, 18(4): 490-493. 
[17] J Chen. Research on flow feedback hydraulic elevator speed control system based on software calculation. Hangzhou: Zhejiang University, 2003. (in Chinese)

[18] B Xu, P Dong, J Zhang, et al. Research on a novel flow rate inferential measurement method and its application in hydraulic elevators. Proceedings of the Institution of Mechanical Engineers, Part C: Journal of Mechanical Engineering Science, 2017, 231(2): 372-386.

[19] J Zhang, D Wang, B Xu, et al. Flow control of a proportional directional valve without the flow meter. Flow Measurement and Instrumentation, Elsevier, 2019, 67: 131-141.

[20] J Jones. Developments in design of electrohydraulic control valves from their initial concept to present day design and applications. Melbourne: Workshop on Proportional and Servovalves, 1997.

[21] L Kelly, H-J Haas. Hydraulic proportional valves with digital controllers. International Fluid Power Exposition and Technical Conference, 1996: 196-11.5.

[22] C Boes. The advantages of new proportional and servo valves with integrated digital electronics. Moog Technical Paper, 2003.

[23] China Hydraulics Pneumatics \& Seals Association. Fluid power transmis sion and control technology roadmap. Beijing: Science and Technology of China Press, 2012.

[24] H Heinken, K Krivenkov, S Ulrich, et al. High-pressure electrorheological valve with full pQ-functionality for servohydraulic applications. Journal of Intelligent Material Systems and Structures, 2015, 26(14): 1959-1967.

[25] JY Yang. Direct type pressure and flow rate multiple control valve. Hangzhou: Zhejiang University of Technology, 2006. (in Chinese)

[26] R B Walters. Hydraulic and electric-hydraulic control systems. Dordrecht, The Netherlands: Kluwer academic publishers, 2000.

[27] Tinsley (Industrial Instruments) Ltd., D C Gall, F L Steghart. Improvements in or relating to servo systems: UK, GB14702/46A. 1949-03-29. https://patents.google.com/patent/GB620688A/en.

[28] P Tamburrano, A R Plummer, E Distaso, et al. A review of electro-hydraulic servovalve research and development. International Journal of Fluid Power, 2018: 1-23.

[29] YX Lu. Historical progress and prospects of fluid power transmission and control. Chinese Journal of Chemical Engineering, 2010, 10(46): 1-9.

[30] G M Wu, MX Qiu, Q FWang. Electrohydraulic proportional technique in theory and application. Hangzhou: Zhejiang University Press, 2006.

[31] M Goldfarb, E J Barth, K B Fite, et al. High bandwidth rotary servo valves. Patent 7,322,375. 2008-1-29.

[32] FT Brown, I S CTentarell, S Ramachandran. A hydraulic rotary switched inertance servo-transformer. Journal of Dynamic Systems, Measurement, and Control, 1988, 110(2): 144-150.

[33] M Pan, N Johnston, J Robertson, et al. Experimental investigation of a switched inertance hydraulic system with a high-speed rotary valve. Journal of Dynamic Systems, Measurement, and Control, 2015, 137(12), https://doi.org/10.1115/1.4031325.

[34] DT Branson, D N Johnston, D G Tilley, et al. Piezoelectric actuation in a high bandwidth valve. Ferroelectrics, 2010, 408: 32-40.

[35] C Han, S-B B Choi, Y-M M Han. A piezoelectric actuator-based directdrive valve for fast motion control at high operating temperatures. Applied Sciences, 2018, 8(10): 1806.

[36] P A Sente, F M Labrique, P J Alexandre. Efficient control of a piezoelectric linear actuator embedded into a servo-valve for aeronautic applications. IEEE Transactions on Industrial Electronics, 2012, 59(4): 1971-1979.

[37] J Jeon, C Han, J U Chung, et al. Performance evaluation of a piezoactuator-based single-stage valve system subjected to high temperature. Smart Materials and Structures, 2015, 24(1): https://iopscience.iop.org/ article/10.1088/0964-1726/24/1/015022.

[38] Z Yang, Z He, F Yang, et al. Design and analysis of a voltage driving method for electro-hydraulic servo valve based on giant magnetostrictive actuato. International Journal of Applied Electromagnetics and Mechanics, 2018, 57(4): 439-456.

[39] Z Yang, Z He, D Li, et al. Hydraulic amplifier design and its application to direct drive valve based on magnetostrictive actuator. Sensors and Actuators A: Physical, 2014, 216: 52-63.

[40] S Karunanidhi, M Singaperumal. Design, analysis and simulation of magnetostrictive actuator and its application to high dynamic servo valve. Sensors and Actuators A: Physical, 2010, 157(2): 185-197.
[41] S Nalbach, P Motzki, S Seelecke. SMA-based hydraulic switching valve. ASME 2015 Conference on Smart Materials, Adaptive Structures and Intelligent Systems, SMASIS 2015, 2015, 2(3): 1-9.

[42] A Zhang, FTu, K Chen, et al. A type of MSMA electro-hydraulic servo valve based on neural network inverse system control. Proceedings of the 32nd Chinese Control Conference, IEEE, 2013: 1013-1016.

[43] N Lucian, R Olivier, M Hubertus. A control approach for fast voice coil actuators for servo valve applications in mobile and industrial hydraulics. Aachen: 11th International Fluid Power Conference, 2018: 318-329.

[44] SWu, Z Jiao, L Yan, et al. Development of a direct-drive servo valve with high-frequency voice coil motor and advanced digital controller. IEEE/ ASME Transactions on Mechatronics, 2013, 19(3): 932-942.

[45] K Abuowda, S Noroozi, M Dupac, et al. A dynamic model and performance analysis of a stepped rotary flow control valve. Proceedings of the Institution of Mechanical Engineers, Part I: Journal of Systems and Control Engineering, 2019, 233(9): 1195-1208.

[46] J Lux, C Habegger. New generation of intelligent electromechanical valve actuation. Aachen 11th International Fluid Power Conference, 2018: 394-403.

[47] F Imaduddin, S A Mazlan, M A A Rahman, et al. A high performance magnetorheological valve with a meandering flow path. Smart Materials and Structures, 2014, 23(6), https://doi.org/10.1088/09641726/23/6/065017.

[48] B Jin, Y G Zhu, W Li. PID parameters tuning of proportional directional valve based on multiple orthogonal experiments method: Method and experiments. Manufacturing Engineering and Process II. Trans. Tech. Publications Ltd., 2013, 325: 1166-1169.

[49] KJ Åström, T Hägglund. PID controllers: theory, design, and tuning. Instrument society of America Research Triangle Park, NC, 1995, 2.

[50] G P Liu, S Daley. Optimal-tuning nonlinear PID control of hydraulic systems. Control Engineering Practice, 2000, 8(9): 1045-1053.

[51] J B Gamble. Sliding mode control system. U.S. Patents, 1994.

[52] J B Gamble. Robust sliding mode control of hydraulic valves. IEE Colloquium on Advances in the Application of Robust Controllers, 1993: 1-4.

[53] J B Gamble, N D Vaughan. Comparison of sliding mode control with state feedback and PID control applied to a proportional solenoid valve. Journal of Dynamic Systems, Measurement and Control, Transactions of the ASME, 1996, 118(3): 434-438.

[54] J H Fang, Z Chen, J H Wei. Some practical improvements of slidingmode control for servo-solenoid valve. Proceedings of the Institution of Mechanical Engineers. Part I: Journal of Systems and Control Engineering, 2016, 230(7): 591-609.

[55] Y Xiong, J Wei, R Feng. Adaptive robust control of a high-response dual proportional solenoid valve with flow force compensation. Proceedings of the Institution of Mechanical Engineers. Part I: Journal of Systems and Control Engineering, 2015, 229(1): 3-26.

[56] W Shi, J Wei, J Fang. Desired compensation nonlinear cascade control of high-response proportional solenoid valve based on reduced-order extended state observer. IEEE Access, 2018, 6: 64503-64514.

[57] J Zhang, Z Lu, B Xu, et al. Investigation into the nonlinear characteristics of a high-speed drive circuit for a proportional solenoid controlled by a PWM signal. IEEE Access, 2018, 6: 61665-61676.

[58] Z Lu, J Zhang, B Xu, et al. Deadzone compensation control based on detection of micro flow rate in pilot stage of proportional directional valve. ISA Transactions, 2019, 94: 234-245.

[59] M Choux, G Hovland. Adaptive backstepping control of nonlinear hydraulic-mechanical system including valve dynamics. Mic: Modeling Identification and Control, Div. Eng. Cybernetics, 2010, 31(1): 35-44.

[60] W Gu, J Yao, Z Yao, et al. Robust adaptive control of hydraulic system with input saturation and valve dead-zone. IEEE Access, 2018, 6: 53521-53532.

[61] C Krimpmann, T Beryram, G Schoppel, et al. Adaptive sliding mode control of a pressure relief valve. e \& i Elektrotechnik und Informationstechnik, 2016, 133(6): 261-265.

[62] Z Xie. Effect of flow forces on a flow control variable force solenoid. SAE International, 2011.

[63] M-H H Yoon, Y-Y Y Choi, J-P P Hong. Improvement in thrust force estimation of solenoid valve considering minor hysteresis loop. AIP Advances, 2017, 7(5): 056607. 
[64] E Canuto, W Acuna-bravo, M Agostani, et al. Proportional electroHydraulic valves: From analogue to digital control. International Journal of Mechatronics and Automation, 2014, 4(2): 93-103.

[65] A Makarow, M Keller, C Rosmann, et al. Model predictive trajectory set control for a proportional directional control valve. 2017 IEEE Conference on Control Technology and Applications (CCTA), IEEE, 2017: 1229-1234.

[66] J Nurmi, M M Aref, J Mattila. A neural network strategy for learning of nonlinearities toward feed-forward control of pressure-compensated hydraulic valves with a significant dead zone. BATH/ASME 2018 Symposium on Fluid Power and Motion Control. American Society of Mechanical Engineers Digital Collection, 2018.

[67] A Jansson, J-O Palmberg. Separate controls of meter-in and meter-out orifices in mobile hyraulic systems. SAE Transactions, 1990: 377-383.

[68] B Eriksson. Mobile fluid power systems design: with a focus on energy efficiency. Linköping University Electronic Press, 2010.

[69] A Hansen, H Pedersen, T Andersen, et al. Investigation of energy saving separate meter-in separate meter-out control strategies. 12th Scandinavian International Conference on Fluid Power, SICFP'11, Tampere University Press, 2011.

[70] B Yao, S Liu. Energy-saving control of hydraulic systems with novel programmable valves. Proceedings of the 4th World Congress on Intelligent Control and Automation (Cat. No.02EX527), 2002, 4: 3219-3223.

[71] M Vukovic, H Murrenhoff. Single edge meter out control for mobile machinery, 2014, ASME/BATH.

[72] ZY Lu, J H Zhang, B Xu, et al. A novel proportional directional valve with independently controlled pilot stage. The 10th JFPS International Symposium on Fluid Power, Fukuoka, 2017.

[73] J H Zhang, ZY Lu, B Xu, et al. Investigation on the dynamic characteristics and control accuracy of a novel proportional directional valve with independently controlled pilot stage. ISA Transactions, 2019, 93: 218-230.

[74] R Q Ding. The multi-mode control method of the independent metering system and its application in mobile machinery. Hangzhou: College of Mechanical Engineering, Zhejiang University, 2015.

[75] M Linjama. Digital fluid power - state of the art. The Twelfth Scandinavian International Conference on Fluid Power, 2011, 2(4): 18-20.

[76] D Fan, J D Yang, D Jing, et al. Advances on high-speed on-off valves. Chinese Journal of Construction Machinery, 2011, 9(3): 351-358.

[77] HY Yang, S Wang, B Zhang, et al. Development and prospect of digital hydraulic valve and valve control system. Journal of Jilin University (Engineering and Technology Edition), 2016, 46(5): 1494-1505.

[78] Y Chen, M Pan, A Plummer. A review of switched inertance hydraulic converter technology. BATH/ASME 2018 Symposium on Fluid Power and Motion Control, American Society of Mechanical Engineers Digital Collection, 2018.

[79] J H Zhang, M S Yang, B Xu. Design and experimental research of a miniature digital hydraulic valve. Micromachines, 2018, 9(6), DOI: https:// doi.org/10.3390/mi9060283.

[80] M S Yang, J H Zhang, B Xu. Experimental study and simulation analysis on electromagnetic characteristics and dynamic response of a new miniature digital valve. Advances in Materials Science and Engineering, 2018: 1-8.

[81] M Linjama, M Vilenius. Digital hydraulic control of a mobile machine joint actuator mockup. Power Transmission and Motion Control: PTMC, PTMC 2004, 2007, 7: 145.

[82] M Linjama, M Vilemius, P O Box, et al. Energy-efficient motion control of a digital hydraulic joint actuator. Proceedings of the JFPS International Symposium on Fluid Power. The Japan Fluid Power System Society, 2005, 2005(6): 640-645.

[83] T Lantela, M Pietola. High-flow rate miniature digital valve system. International Journal of Fluid Power, 2017, 18(3): 188-195.

[84] M Paloniitty, M Linjama, K Huhtala. Concept of digital microhydraulic valve system utilising lamination technology. Proceedings of the 9 th International Fluid Power Conference, 2014, 1: 303-313.

[85] H Murrenhoff. Trends in valve development. Ölhydraulik und Pneumatik, 2003, 46(4): 1-36.

[86] G Keuper, R Romes, H Sandau. New valve concepts and CAN based data link for tractor hydraulics. VDI Berichte, 1996, 1297: 61-64.

[87] L Weibo. Study on intelligent valve and its signal extraction and two-line transmission mode based on field bus. Hangzhou: Zhejiang University, 2002
[88] G W Li, L L Jin, Y Lin, et al. The development and prospect of electrohydraulic proportional directional valve. Hydraulics Pneumatics \& Seals, 2018, 38(3): 1-4.

[89] R Isermann. Fault-diagnosis applications: model-based condition monitoring: actuators, drives, machinery, plants, sensors, and fault-tolerant systems. Springer Science \& Business Media, 2011.

[90] J Watton. Modelling, monitoring and diagnostic techniques for fluid power systems. Springer Science \& Business Media, 2007.

[91] B Beck, J Weber. Enhancing safety of independent metering systems for mobile machines by means of fault detection. Linköping: Linköping University Electronic Press, 2017

[92] H Raduenz, F J Souza. Evaluation of an on-line fault detection method for proportional hydraulic valves. 9th FPNI Ph.D. Symposium on Fluid Power. American Society of Mechanical Engineers Digital Collection, 2016.

[93] H Raduenz, Y E A Mendoza, D Ferronatto, et al. Online fault detection system for proportional hydraulic valves. Journal of the Brazilian Society of Mechanical Sciences and Engineering, 2018, 40(7): 331.

[94] S Sharifi, A Tivay, S M Rezaei, et al. Leakage fault detection in electrohydraulic servo systems using a nonlinear representation learning approach. ISA Transactions, 2018, 73: 154-164.

[95] S Sharifi, S M Rezaei, A Tivay, et al. Multi-class fault detection in electrohydraulic servo systems using support vector machines. 4th International Conference on Robotics and Mechatronics (ICROM). IEEE, 2016.

[96] X Zhao, S Zhang, C Zhou, et al. Experimental study of hydraulic cylinder leakage and fault feature extraction based on wavelet packet analysis. Computers and Fluids, Elsevier Ltd, 2015, 106: 33-40.

[97] F Chao. Study on fault diagnosis method of solenoid valve. Wuhan: Huazhong University of Science and Technology, 2017.

[98] L Wang, W D Qu. Fault diagnosis of servo valve with PCA-SVM. Process Automation Instrumentation, 2013(01): 25-28+31. (in Chinese)

[99] B Pan, J Q Xiong. The application of multi-sensor information fusion in the intelligent fault diagnosis of hydraulic system. Machine Tool \& Hydraulics, 2006, 5.

[100] L Lei. Fault diagnosis and analysis of electro-hydraulic servo valve based on genetic optimization BP neural network. Qinhuangdao: Yanshan University, 2015

[101] CY Liu, L P Fan. Research on RBF-BP neural network fault diagnosis algorithm of electro-hydraulic servo valve based on genetic optimization. Journal of Shenyang University of Chemical Technology, 2015, 29(1): 49-53. (in Chinese)

[102] C Li. Fault diagnosis of electro-hydraulic servo valve based on BP neural network. Wuhan: Wuhan University of Science and Technology, 2010. (in Chinese)

[103] S Q Hao. Study on on-line fault intelligent diagnosis of hydraulic AGC servo valve. Shanghai: Shanghai Jiaotong University, 2010. (in Chinese)

[104] L D Fu, K S Chen, L C Zeng, et al. Study on improved intelligent fault diagnosis of electro-hydraulic servo valve. Journal of Wuhan University of Science and Technology, 2007, 30(2): 164-167. (in Chinese)

[105] S B Tan, J C Liu. Fault diagnosis of electro-hydraulic servo valve based on neural network. 2011 International Conference on Electric Information and Control Engineering. IEEE, 2011:3274-3276.

[106] L Fu, K Chen, J Yu, et al. The fault diagnosis for electro-hydraulic servo valve based on the improved genetic neural network algorithm. 2006 International Conference on Machine Learning and Cybernetics. IEEE, 2006 2995-2999.

[107] H M Liu, S P Wang, P C Ouyang. Fault diagnosis in a hydraulic position servo system using RBF neural network. Chinese Society of Aeronautics and Astronautics, 2006, 19(4): 346-353.

[108] H M Liu, S P Wang, P C Ouyang. Fault diagnosis based on improved Elman neural network for a hydraulic servo system. 2006 IEEE Conference on Robotics, Automation and Mechatronics, 2006.

[109] H M Liu, J C Zhang, C Lu. Performance degradation prediction for a hydraulic servo system based on Elman network observer and GMM-SVR. Applied Mathematical Modelling, Elsevier Inc., 2015, 39(19): 5882-5895.

[110] L Hu, K Cao, H Xu, et al. Fault diagnosis of hydraulic actuator based on least squares support vector machines. IEEE International Conference on Automation and Logistics. IEEE, 2007: 985-989.

[111] L M Hu, K Q Cao, H J Xu. Fault diagnosis of hydraulic steering gear based on regression support vector machine. Journal of System Simulation, 2007, 19(23): 5509-5512. 
[112] K Cao, J Zhang, L Hu. Fault diagnosis of electro-hydraulic position servo closed-loop system based on support vector regression. Proceedings of the IEEE International Conference on Automation and Logistics, ICAL 2007, 2007: 3044-3049.

[113] M Muenchhof, M Beck, R Isermann. Fault-tolerant actuators and drives - Structures, fault detection principles and applications. Annual Reviews in Control, 2009, 33(2): 136-148.

[114] M Samadani, C A Kwuimy, C Nataraj. Fault detection and severity analysis of servo valves using recurrence quantification analysis. Villanova University, Villanova, United States, 2014.

[115] L Borello, MDL Dalla Vedova, G Jacazio, et al. A prognostic model for electrohydraulic servovalves. Annual Conference of the Prognostics and Health Management Society. 2009: 1-12.

[116] W Xuanyin, L Xiaoxiao, L Fushang. Analysis on oscillation in electrohydraulic regulating system of steam turbine and fault diagnosis based on PSOBP. Expert Systems with Applications, 2010, 37(5): 3887-3892.

[117] ZYao. Study on fault diagnosis technology of hydraulic excavator multichannel valve group based on model prediction. Xiangtan: Xiangtan University, 2015. (in Chinese)

[118] P Athanasatos, T Costopoulos. Proactive fault finding in a 4/3-way direction control valve of a high pressure hydraulic system using the bond graph method with digital simulation. Mechanism and Machine Theory, 2012, 50: 64-89.

[119] D G Luenberger. Observing the state of a linear system. IEEE Transactions on Military Electronics, 1964, 8(2): 74-80.

[120] D Min, L Cai. Sensor fault diagnosis of HAGC system for strip rolling mill based on wavelet transform. Journal of Iron and Steel Research, 2006, 18(12): 54

[121] S C Abou, M Kulkarni, M Stachowicz. Actuated hydraulic system fault detection: A fuzzy logic approach. Engineering Letters, 2010, 18(1).

[122] H Khan, S C Abou, N Sepehri. Nonlinear observer-based fault detection technique for electro-hydraulic servo-positioning systems. Mechatronics, 2005, 15(9): 1037-1059.

[123] A S Rezazadeh, H R Koofigar, S Hosseinnia. Robust leakage detection for electro hydraulic actuators using an adaptive nonlinear observer. International Journal of Precision Engineering and Manufacturing, 2014, 15(3): 391-397.

[124] Q N Xu, K M Lee, H Zhou, et al. Model-based fault detection and isolation scheme for a rudder servo system. IEEE Transactions on Industrial Electronics, 2014, 62(4): 2384-2396.

[125] Q N Xu. Study on fault diagnosis of electro-hydraulic servo system of Marine steering gear based on uncertain model. Hangzhou: Zhejiang University, 2015

[126] P Garimella, B Yao. Robust model-based fault detection using adaptive robust observers. Proceedings of the 44th IEEE Conference on Decision and Control, IEEE, 2005: 3073-3078.

[127] P Garimella, B Yao. Model based fault detection of an electro-hydraulic cylinder. Proceedings of the 2005, American Control Conference, 2005: 484-489.

[128] S Gayaka, B Yao, P Meckl. Fault detection for nonlinear systems in presence of input unmodeled dynamics. IEEE/ASME International Conference on Advanced Intelligent Mechatronics, AIM, 2007.
[129] S Gayaka, B Yao. Fault detection, identification and accommodation for an electro-hydraulic system: An adaptive robust approach. IFAC Proceedings Volumes, 2008, 41(2): 13815-13820.

[130] H Alwi, C Edwards. Application of second order sliding mode observers for fault reconstruction on the ADDSAFE benchmark. AIAA Guidance, Navigation, and Control Conference 2011, 2011: 1-24.

[131] L Liu. Research on additive fault detection and fault-tolerant control strategy of electromechanical hydraulic servo system based on sliding mode. Nanjing: Nanjing University of Science and Technology, 2016. (in Chinese)

[132] I Arasaratnam, S Haykin. Cubature kalman filters. IEEE Transactions on Automatic Control, 2009, 54(6): 1254-1269.

[133] J Dunik, O Straka, M Šimandl. Stochastic integration filter. IEEE Transactions on Automatic Control, 2013, 58(6): 1561-1566.

[134] X Wang, V L Syrmos. Fault detection, identification and estimation in the electro-hydraulic actuator system using EKF-based multiple-model estimation. 2008 16th Mediterranean Conference on Control and Automation. IEEE, 2008: 1693-1698.

[135] P A Halder. A novel approach for detection and diagnosis of process and sensor faults in electro-hydraulic actuator. Int. J. Engineering Research and Development, 2013, 6(7): 15-22.

[136] P Halder, S Mukhopadhyay, et al. Detection and diagnosis of process and sensor faults in electro-hydraulic actuator using extended Kalman filter (EKF). Proceedings of Advances in Control and Optimization of Dynamic Systems, 2012.

[137] L An, N Sepehri. Hydraulic actuator leakage quantification scheme using extended Kalman filter and sequential test method. 2006 American Control Conference, IEEE, 2006.

[138] L An, N Sepehri. Hydraulic actuator leakage fault detection using extended Kalman filter. International Journal of Fluid Power, 2005, 6(1): 41-51.

[139] L An. Actuator leakage fault detection and isolation based on extended Kalman filtering scheme. University of Manitoba, 2007.

[140] S Julier, J Uhlmann, H F Durrant-Whyte. A new method for the nonlinear transformation of means and covariances in filters and estimators. IEEE Transactions on Automatic Control, 2000, 45(3): 477-482.

[141] D Simon. Optimal state estimation: Kalman, H infinity, and nonlinear approaches. John Wiley \& Sons, 2006.

[142] M Sepasi, F Sassani. On-line fault diagnosis of hydraulic systems using unscented Kalman filter. International Journal of Control, Automation and Systems, 2010, 8(1): 149-156.

[143] J Nurmi, J Mattila. Detection and isolation of leakage and valve faults in hydraulic systems in varying loading conditions, Part 2: fault detection and isolation scheme. International Journal of Fluid Power, 2012, 13(1): 17-27.

[144] J Nurmi, J Mattila. Detection and isolation of faults in mobile hydraulic valves based on a reduced-order model and adaptive thresholds. ASME/BATH 2013 Symposium on Fluid Power and Motion Control. American Society of Mechanical Engineers Digital Collection, 2013.

\section{Submit your manuscript to a SpringerOpen ${ }^{\circ}$ journal and benefit from:}

- Convenient online submission

- Rigorous peer review

- Open access: articles freely available online

- High visibility within the field

Retaining the copyright to your article

Submit your next manuscript at springeropen.com 